\title{
Redefining thirst: A conceptual four-compartment model characterising types of thirst, and their underlying mechanisms and interactions
}

Harriet A. Carroll, BA, MSc, MRes, PhD

Cardiovascular Research-Hypertension, Clinical Research Centre, Lund University, Malmö, Sweden

Hc12591@my.bristol.ac.uk

Key words: acetylcholine; ageing; appetite; COVID19; dry mouth; exercise; hydration; MDMA; osmolality; sensory-specific satiety; thirst; xerostomia

Conflicts of interest: HAC has received research funding from the Economic and Social Research Council, the European Hydration Institute, and the Esther Olssons stiftelse II \& Anna Jönssons Minnesfond; has conducted research for Tate \& Lyle; and has received conference, travel and accommodation fees from Danone Nutritia Research. 


\begin{abstract}
Currently, the conceptualisation of thirst is based nearly entirely on osmoregulation, with some acknowledgement of anticipatory-thirst, though with no testable mechanism. Such a model of thirst is unable to explain many thirst-related phenomena, such as why drinking can occur with hypotonicity, or how quantity of intake at a drinking occasion is regulated. Herein, I aim to unify various lines of thinking from different disciplines surrounding thirst and body water regulation by presenting a four-compartment model comprising of both primary and secondary thirsts: true-thirst (osmo-regulated); contextual-thirst (e.g. mouth-breathing); pharmacological-thirst (induced from drugs); and impulsive-thirst (everyday spontaneous drinking). Within this framework, a differentiation of thirst and dry mouth is presented, with further differentiation between dry mouth ('true-xerostomia', hyposalivation) and the sensation of dry mouth ('sensational-xerostomia', a typically non-overwhelming desire to drink). Based off pharmacological-thirst mechanisms, the cholinergic system is proposed to initiate impulsive-thirst by triggering a (sensation of) dry mouth in everyday life (i.e. without hypertonicity). Following this, psychological food-appetite constructs that are centrally regulated (sensory-specific satiety, palatability, and pleasantness) are applied to thirst to explain quantities of fluid consumed, termination of drinking, and drinking patterns in everyday life, as well as offer further insights into how drinking habits are formed. The historical context is also provided, demonstrating that most of these are not new ideas in isolation, but combining them to create a unified model of thirst has not previously been attempted. Finally, ageing-, exercise-, alcohol-hangover-, and 3,4methylenedioxymethamphetamine-induced thirst are explained by the model presented, given as examples of dysregulated hydration physiology causing thirst or drinking behaviours currently unexplainable by true osmoregulatory or anticipatory-thirst. Whilst some anomalies still remain, all these examples have some form of dysregulated cholinergic activity as a commonality. It is likely this model is incomplete and ideas for further exploration are presented with the hope that the conceptual model can be investigated, validated, refined, and developed further as appropriate. Overall, this thesis outlines a fourcompartment model of thirst regulation (at least partially) explaining several outstanding questions relating to drinking behaviours.
\end{abstract}




\section{Contents}

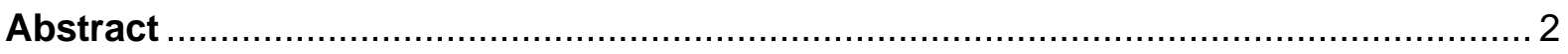

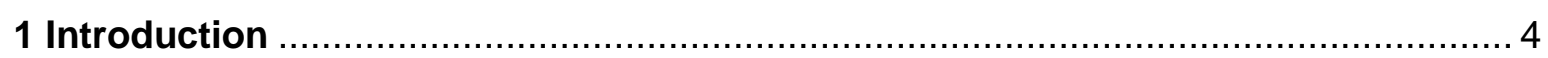

2 Redefining thirst: A conceptual four-compartment model ................................. 5

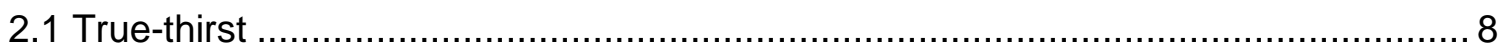

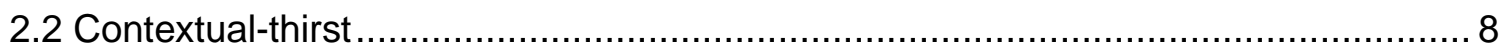

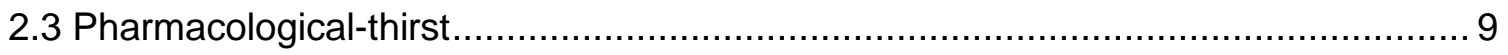

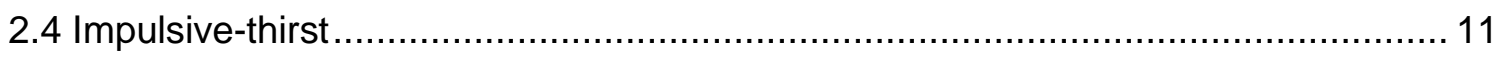

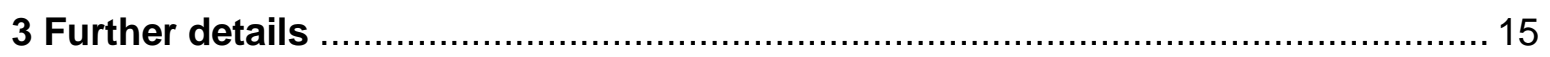

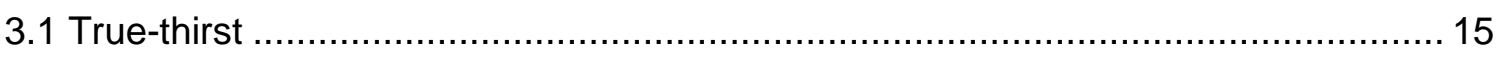

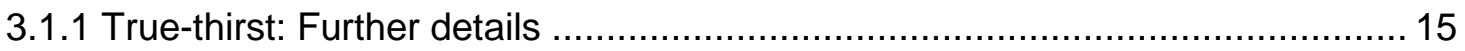

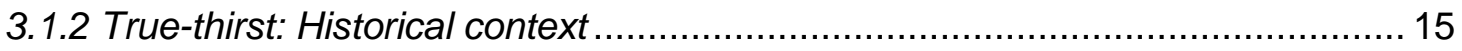

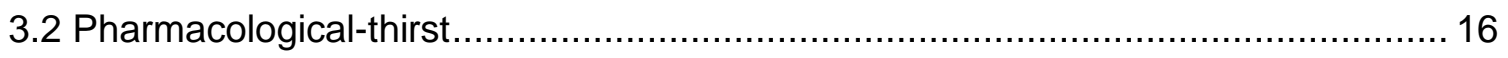

3.2.1 Pharmacological-thirst: Further details................................................... 16

3.2.2 Pharmacological-thirst: Historical context .............................................. 17

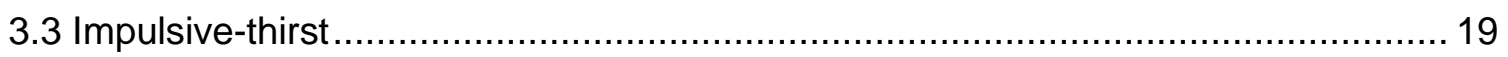

3.3.1 Impulsive-thirst: Further details_hedonic rewards ..................................... 19

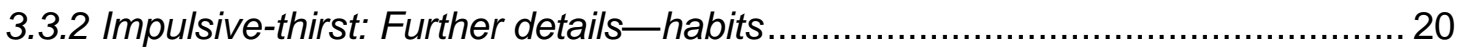

3.3.3 Impulsive-thirst: Historical context....................................................... 22

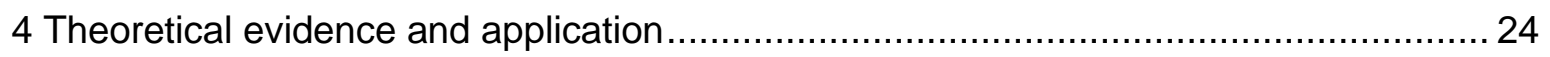

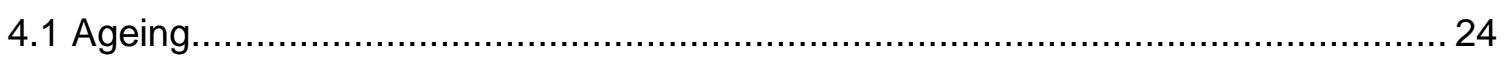

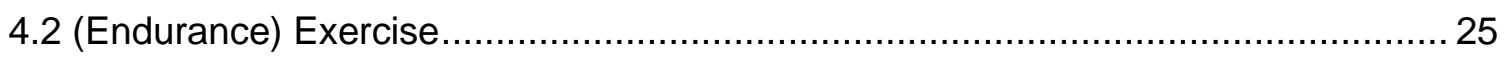

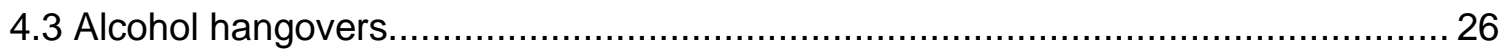

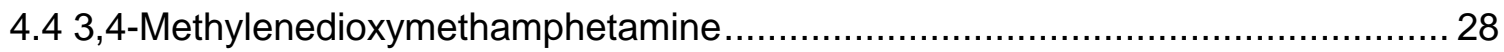

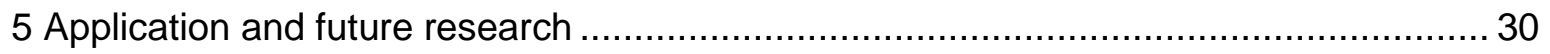

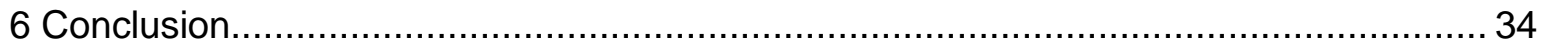

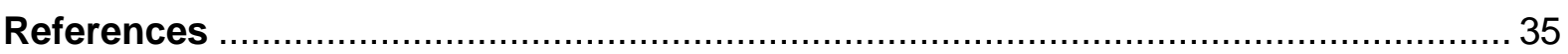




\section{Introduction}

Thirst is a well-established sensation describing the desire to drink. This fascinating appetite is responsible for keeping us alive via maintaining our body water; an inhibition of which can cause death within a matter of days. Despite its importance, compared to other appetites such as hunger, relatively little research has been conducted to understand thirst regulation. As such, research appears to have stagnated, focusing on a narrow spectrum of work relating to osmotic regulation conducted primarily in the early 1900s, and $\sim 1970$ s. Although current research is building on this work, the scope is somewhat myopic-using the same framework from the 1970s with updated and more advanced methods.

This work is of course essential in understanding thirst regulation. However, the current model of thirst does not adequately answer several outstanding questions about every day body water regulation. Currently, several disciplines follow different lines of thinking: because there is ample evidence that thirst can be satiated without oropharyngeal sensations, the most common present line of thinking in the hydration and health community relates to thirst as a central osmo-regulated sensation. Conversely, psychologists note that oropharyngeal sensations do appear to influence fluid-seeking and ingestive behaviours. Equally, dental and oral hygienists and pharmacologists have taken their own view and largely focus on oropharyngeal sensations but from a physiological (rather than psychological) perspective, largely disregarding osmo-reception. These debates have been ongoing since at least the 1800 s with limited attempts to put the various ideas into one model (key aspects of these debates are outlined in section 3, but Fitzsimons [1972] provides an excellent and detailed account). This thesis aims to summarise these various perspectives in order to create a more unified and complete theory of thirst and therefore body water regulation.

Herein I outline our current model of thirst regulation, then propose three more subtypes of thirst in order to explain some of the remaining anomalies, taking a critical historical perspective. Each thirst subtype is described below with the known or proposed mechanism(s). The basic theory will first be presented (section 2 ) followed by describing further details and the historical context (section 3), and ending with current thirst anomalies demonstrating how the conceptual four-compartment model described might explain currently inadequately explained water-seeking behaviours (section 4). Lastly, areas in which the proposed four compartment model may be incomplete are presented as ideas for future investigation (section 5). 


\section{Redefining thirst: A conceptual four-compartment model}

38 The crux of this theory is that there are at least four types of thirst: true-thirst, contextualthirst, pharmacological-thirst, and impulsive-thirst (see Table 1 for brief definitions). Figure 1 outlines the four proposed subtypes of thirst and their interactions, though it is acknowledged that this is most likely an incomplete model. Table 2 additionally shows key outstanding scenarios regarding thirst regulation and demonstrates the subtype(s) of thirst that offer a potential explanation. Future research may find (for example) more subtypes, or recategorise such that examples in each subtype become independent.

Table 1. Definitions and key mechanisms of the proposed four subtypes of thirst

\begin{tabular}{|c|c|c|c|}
\hline & Definition & Key mechanism(s)* & Other comments \\
\hline True thirst & $\begin{array}{l}\text { Osmolality- } \\
\text { regulated }\end{array}$ & $\begin{array}{l}\text { Hypertonicity being detected by } \\
\text { magnocellular neurons }\end{array}$ & \\
\hline $\begin{array}{l}\text { Contextual } \\
\text { thirst }^{*}\end{array}$ & $\begin{array}{l}\text { External and/or } \\
\text { environmental } \\
\text { variables that incite } \\
\text { drinking behaviours }\end{array}$ & $\begin{array}{l}\text { Context dependent, e.g. } \\
\text { increased saliva evaporation, } \\
\text { access to fluids }\end{array}$ & $\begin{array}{l}\text { Examples: habit, } \\
\text { environment, mouth- } \\
\text { breathing, purpose } \\
\text { (e.g. caffeine) }\end{array}$ \\
\hline $\begin{array}{c}\text { Pharmacological } \\
\text { thirst }\end{array}$ & $\begin{array}{l}\text { Xerostomia from } \\
\text { pharmaceutical } \\
\text { drugs }\end{array}$ & Changes in cholinergic activity & $\begin{array}{l}\text { See Scully (2003) for } \\
\text { other (less congruent) } \\
\text { mechanisms }\end{array}$ \\
\hline Impulsive thirst* & $\begin{array}{l}\text { Experiential } \\
\text { sensations that } \\
\text { result in } \\
\text { maintaining our } \\
\text { daily body water in } \\
\text { everyday life }\end{array}$ & $\begin{array}{l}\text { Fluctuations in cholinergic } \\
\text { activity causing true- or } \\
\text { sensational-xerostomia inducing } \\
\text { thirst/drinking, and quantity of } \\
\text { fluid regulated by palatability } \\
\text { and sensory-specific satiety }\end{array}$ & $\begin{array}{l}\text { Likely several other } \\
\text { factors involved (see } \\
\text { Table 4) }\end{array}$ \\
\hline
\end{tabular}

${ }^{*}$ Key mechanisms are proposed and as of yet not fully tested or established 


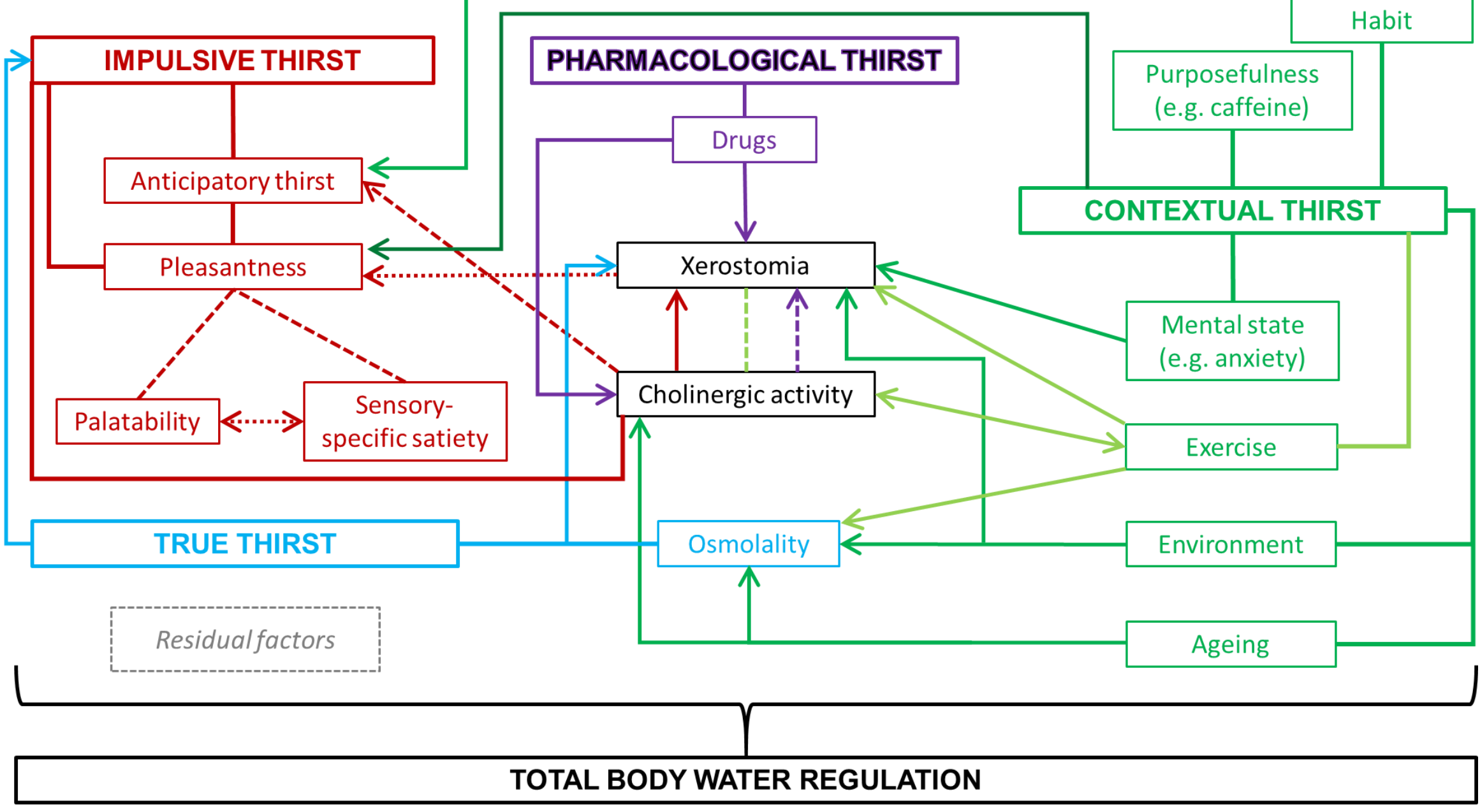

Figure 1. Systems map of the four proposed subtypes of thirst (true-thirst, contextual-thirst, pharmacological-thirst, and impulsive-thirst) and their interactions. Solid lines are direct relationships (with arrows indicating directionality if necessary; dashed lines represent mediating relationships; dotted lines represent moderating relationships. Xerostomia may represent true- or sensational-xerostomia. Residual factors are any unmentioned or undiscovered factors that likely have a role in any part of the model (e.g. those outlined in Table 4). Lines emanating from exercise is in light green to show the mediating relationship between xerostomia and cholinergic activity is exercise-induced (i.e. not any of the other contextual factors); the dark green line emanating from contextual thirst to palatability demonstrates that some (e.g. exercise, purposefulness) but not all contexts might lead to a change in pleasantness 
Table 2. Questions each type of thirst can help explain

\begin{tabular}{|c|c|c|c|c|}
\hline Question & True-thirst & Contextual-thirst & $\begin{array}{l}\text { Pharmacological- } \\
\text { thirst }\end{array}$ & Impulsive-thirst \\
\hline $\begin{array}{l}\text { How can marathon-runners and ecstasy-users drink themselves } \\
\text { sometimes to death, despite hyponatraemia? }\end{array}$ & & $\checkmark$ & & $\checkmark$ \\
\hline $\begin{array}{l}\text { Why are some people high-fluid drinkers, whilst others low-fluid } \\
\text { drinkers? }\end{array}$ & & $\checkmark$ & & $\checkmark$ \\
\hline $\begin{array}{l}\text { Why do we not wait until we are under- or hypohydrated before } \\
\text { feeling the urge to drink during every day life? }\end{array}$ & & $\checkmark$ & & $\checkmark$ \\
\hline $\begin{array}{l}\text { Why does the taste of water satiate thirst, despite hydration } \\
\text { physiology (i.e. hyperosmolality) remaining unchanged? }\end{array}$ & & & & $\checkmark$ \\
\hline Why do we not (typically) wake up at night to drink? & & & & $\checkmark$ \\
\hline $\begin{array}{l}\text { Why do thirst responses and drinking behaviours, contrary to what } \\
\text { would be expected in terms of their hydration physiology, decline } \\
\text { with age? }\end{array}$ & & $\checkmark$ & & $\checkmark$ \\
\hline How is everyday drinking regulated? & $\checkmark$ & $\checkmark$ & & $\checkmark$ \\
\hline How are drinking habits formed? & & & & $\checkmark$ \\
\hline $\begin{array}{l}\text { Why do people who are not on medication feel thirsty or suffer with } \\
\text { xerostomia? }\end{array}$ & $\checkmark$ & $\checkmark$ & & $\checkmark$ \\
\hline $\begin{array}{l}\text { Why do we sometimes sip and sometimes gulp drinks, i.e. what } \\
\text { determines the quantity of fluid ingested at each drinking occasion? }\end{array}$ & & $\checkmark$ & & $\checkmark$ \\
\hline $\begin{array}{l}\text { Why do certain drugs give xerostomia regardless of environment, } \\
\text { drinking habits, or hydration status? }\end{array}$ & & & $\checkmark$ & \\
\hline Why does thirst alter with food (solute) intake? & $\checkmark$ & & & \\
\hline Why does drinking increase before/with food intake? & & & & $\checkmark$ \\
\hline
\end{tabular}




\subsection{True-thirst}

Summary: True-thirst is the overwhelming and unignorable desire to consume fluid, driven primarily by hypertonicity

This is the classic model of osmotically-regulated thirst and is what most recent thirst-related research has focused on. It is often called homeostatic thirst (or primary drinking), but this label has been avoided here as by the time true-thirst occurs, body-water homeostasis is (nearly) disrupted. In other words, osmo-regulated thirst is a response to a (near) disruption of homeostasis (Fitzsimons, 1972; Levitt \& Fisher, 1966), rather than something that maintains current homeostasis. Several excellent reviews have been written on true-thirst; these provide greater detail on several aspects of thirst not discussed in-depth herein, such as neurological true-thirst regulation, the renin-angiotensin-aldosterone system, compartmental dehydration, and eating-drinking interactions (e.g. Armstrong \& Kavouras, 2019; Fitzsimons, 1972).

In brief, true-thirst arises primarily from inadequate fluid intake resulting in an elevation of serum osmolality. There are several other hypohydration mechanisms contributing to truethirst (e.g. hypovolemia, the renin-angiotensin-aldosterone system) which are not discussed further in part because these are also typically related to osmo-regulation. Osmolality is tightly controlled, typically within $10 \mathrm{mmol} \cdot \mathrm{L}^{-1}$, thus small deviations are accurately detected via both the vagus nerve and magnocellular neurons in the brain (Sharif-Naeini et al., 2008). True-thirst typically occurs after $\sim 1 \%$ increase in plasma tonicity (Wolf, 1950).

Multiple areas of the brain have stretch-sensitive ion channels, meaning they can detect osmolality changes. These areas include, but are not exclusive of, the supraoptic nucleus, and the organum vasculosum of the lamina terminalis (Johnson, 2007; Sharif-Naeini et al., 2008). The stretch-sensitive ion channels act as osmoreceptors stimulating magnocellular neurons in the paraventricular nucleus and supraoptic nucleus, resulting in arginine vasopressin (AVP) secretion (Robertson, 1984; Thornton, 2010). The secretion of AVP reduces urinary output in order to preserve body water. At this point a person is either underhydrated (i.e. their total body water is the roughly unchanged but they are having a physiological response preserve body water; Kavouras, 2019), or they are already hypohydrated (i.e. body water has been reduced).

From this point of under- or hypohydration, true-thirst is induced eliciting fluid-seeking and consumption behaviours. Considering how overwhelming true-thirst can be (Robertson, 1984), unlike other known appetites such as hunger, it seems illogical for true-thirst to be the primary regulator of fluid intake in everyday life.

\subsection{Contextual-thirst}

Summary: Contextual-thirst is drinking behaviours driven by factors unrelated to hydration status, such as habit; the resultant consumption of fluid nevertheless alters hydration physiology

Here, contextual-thirst is defined as external and/or environmental variables that incite drinking behaviours. Examples of contextual-thirst include: habitual drinking, purposeful drinking (e.g. for caffeine or enjoyment), extended talking, cold and/or dry air, mouthbreathing, and/or mood/mental state. Thus, contextual-thirst can be described as a secondary thirst as it is not triggered by hypohydration/hypertonicity (Fitzsimons, 1972). Furthermore, whilst drinking is not initiated by any thirst sensations derived from hydration 
status per se, the resultant ingestion of fluid does alter hydration physiology. As such, it seems reasonable that there is some form of regulation occurring. Part of this regulation may come from interactions with concepts introduced in impulsive thirst (section 2.4).

Some of these scenarios have clear mechanistic aetiologies; for example, mouth-breathing, low humidity, and talking all increase the rate of saliva evaporation from the mouth and result in drinking to mitigate this unpleasant oropharyngeal sensation (Fitzsimons, 1972). Others have more complex mechanisms, for example, depression may lead to increased cortisol and have anticholinergic effects (the role of the cholinergic system is discussed in section 2.3) which in turn reduces salivary flow rate and causes xerostomia (Gholami et al., 2017). The thirst felt in these cases is not true-thirst (as defined above) because blood osmolality has not (necessarily) been altered to trigger drinking. Because of the high correlation between thirst and dry mouth, they are often assumed to be the same, but many have posited they are likely different sensations driving fluid ingestion (Brumstrom, 2002; Inenago \& Ono, 2010). Thus, the importance of these examples of contextual-thirst is that it demonstrates a differentiation between true-thirst and a dry mouth (xerostomia) 'thirst'.

The remaining examples (habitual and purposeful drinking) also have little to do with restoring body water; similar to eating without the stimulus of hunger (Cannon, 1918). These contextual-drinking behaviours may have been formed via various mechanisms, such as physiological feedback mechanisms entrained from early life experiences (Rosinger, 2019; section 3.3.2 discusses habit formation). Contextual-thirst and drinking, however, demonstrates that drinking can occur without body water deficits, or signs typically associated with hypohydration, such as dry mouth. Understanding the regulation of these behaviours could aid in adherence to public health recommendations that are now encouraging water intake.

The idea that healthy people can drink beyond their needs may seem unusual for an appetite in healthy people. Typically we reach food-related satiety (which may be hunger/fullness, or may be a reward-based satiety) and the desire to consume dissipates, resulting in the termination of eating (discussed in section 2.4 and 3.3.1). With fluid, it seems we can be satiated with no physiological (true-thirst/xerostomia) or psychological (reward) need or desire to drink, but can continue drinking anyway due to some other property of the beverage, or out of habit. This is often overlooked, but it is an interesting to consider why drinking can continue far beyond needs/desires in every day life; alternatively, why can drinking be so low as to keep some people in a permanent state of underhydration (Perrier et al., 2013), despite adequate water access. It therefore seems rational that some form of, as yet unknown, regulation is occurring unrelated to pre-ingestive hydration status.

\subsection{Pharmacological-thirst}

Summary: Pharmacological-thirst is the dry mouth (xerostomia) experienced as a result of taking certain pharmaceutical drugs. These drugs have the cholinergic system as a commonality, potentially providing insights into thirst regulation

Pharmacological-thirst is the dry mouth 'thirst' that occurs with certain pharmaceutical drugs. As with contextual-thirst, this is not a true-thirst in that an increase in osmolality or reduction in total body water does not typically occur; rather xerostomia is present and this may drive fluid seeking behaviours and ingestion (i.e. another a form of secondary drinking). As such, this thirst subtype has similarities to contextual-thirst as it is not caused by alterations in tonicity or body water, but the consequence (i.e. drinking or mouth wetting) does alter 
149 hydration physiology. This 'thirst' is much harder to satiate and drinking (or saliva-inducing

150 agents, such as mints) can often offer only minimal and temporary relief (Odusola, 1991;

151 Stewart et al., 1998; Visvanathan \& Nix, 2010).

152

153

154

155

156

157

158

159

160

161

162

163

164

165

166

167

168

169

170

171

172

173

174

175

176

177

178

179

180

181

182

183

184

185

186

187

188

189

190

191

192

193

194

195

196

197

198

199
Several pharmaceutical drugs have xerogenic effects, with several potential underlying mechanisms; a unifying system does appear to have a role in most of the drugs that have xerogenic effects though-the cholinergic system (Scully, 2003). The cholinergic system is part of the autonomic nervous system comprised of muscarinic and nicotinic receptors, with acetylcholine (ACh) as a key neurotransmitter. In terms of hydration, ACh may have antidiuretic effects (Fitzsimons, 1972; Pickford, 1939); a role in the sweat response (Beyer et al., 2017); and an effect on arterial blood pressure regulation (Mangiapane \& Simpson, 1983). More specifically, the muscarinic ACh receptor (mAChR) subtype $M_{3}$ is located in the salivary (among other) glands (though other cholinergic receptors are also implicated in saliva flow). Binding of $A C h$ to salivary $\mathrm{M}_{3}$ receptors causes intracellular $\mathrm{Ca}^{2+}$ concentrations to increase, leading to apical membrane $\mathrm{Cl}^{-}$channel activation, resulting in saliva secretion (Dawson et al., 2005; Sumida et al., 2014). Additionally, $\mathrm{M}_{3}$ receptor activation aids in crossmembrane apical water transport through increased trafficking of aquaporin 5 from the cytoplasm (Li et al., 2004; Sumida et al., 2014).

Further, anticholinergic drugs targeting nicotinic ACh receptors (nAChRs) inhibit saliva production (Sreebny \& Schwartz, 1997). The mechanism for this effect is currently unclear, but some have suggested it might be due to $\mathrm{nAChR}$ activation of muscarinic receptors via cholinergic fibre innervation of the hypothalamus and circumventricular organs (which regulate true-thirst) in which both mAChR and nAChRs are found (Honda et al., 2003; Inenaga \& Ono, 2010; Ono et al., 2008). For example, cholinergic receptors in the subfornical organ have been shown to illicit drinking behaviours in rats (Menani et al., 1984). Importantly, neural cholinergic thirst is independent of osmolality (Grossman, 1962), making it an separate pathway altogether to true-thirst (notwithstanding context-specific interactions).

Whilst xerostomia is a commonly experienced side effect of certain drugs, there appears to be a paucity of research demonstrating whether this sensation results increased fluid intake in humans, though the limited available evidence suggests it perhaps does (Boyd et al., 1997; Daly, 2016; Hopcraft \& Tan, 2010; Närhi et al., 1999). Somewhat speculatively due to the lack of human data and the (mainly animal) methods used to determine cholinergic thirst (section 3.2), there may be two distinct subtypes of cholinergic-thirst: 'true'-xerostomia, and 'sensational'-xerostomia (Inenaga \& Ono, 2010). This idea is supported by the diuretic drug furosemide. Whilst 'dry mouth' is a known side effect, furosemide does not appear to impact several salivary properties (e.g. flow rate, protein, electrolytes), suggesting the sensation of xerostomia is more than just quantitative salivary production (Scully, 2003).

Accordingly, true-xerostomia in this case is the reduction in saliva flow rate (i.e. hyposalivation) causing a literal dry mouth. This is likely, but not definitively, caused (at least in part) by local ACh antagonism of $\mathrm{M}_{3}$ receptors in the salivary glands specifically.

Sensational-xerostomia on the other hand is the feeling or sensation of a dry mouth, without necessarily a reduction in saliva flow; this could be likened to (under everyday conditions)a mild sense of thirst or desire to drink, but is distinct from true-thirst (Inenaga \& Ono, 2010; Levitt \& Fisher, 1967) and may have some bearing to the subtle sensations experienced throughout the day that initiate drinking. Speculatively, this might originate centrally from inhibition of cholinergic activity. Thus, blocking local (i.e. salivary gland) cholinergic activity might have differential effects than blocking central cholinergic activity. Blocking local $\mathrm{M}_{3}$ 
200 ACh activity would reduce saliva flow (true-xerostomia), this in turn might increase drinking regardless of other factors, including central ACh; comparatively, increasing central ACh activity would increase drinking behaviours, and so presumably thirst, regardless of saliva flow rate.

The nuances and complexities of pharmacological-thirst are further discussed in section 3.2; the main purpose of this section was to firstly introduce an often-forgotten subtype of thirst which offers potential mechanistic insight into water body regulation, and secondly demonstrate a clear physiological pathway beyond osmolality that is implicated in thirst. Understanding cholinergic thirst provides a potential mechanism for understanding nonosmotic thirst appetites.

211

212

213

214

215

216

217

218

219

220

221

222

223

\subsection{Impulsive-thirst}

Summary: Impulsive-thirst explains everyday drivers of fluid ingestion; conceptually, drinking is initiated by fluctuations in cholinergic activity, and inhibited by the interaction between palatability and sensory-specific satiety

Impulsive-thirst is another form of secondary drinking, which I have defined as the experiential sensations that result in maintaining our daily body water in everyday life, and causes us to drink regardless of the aforementioned other types of thirst. It can therefore be classed as a regulatory thirst aiming to maintain body water (Fitzsimons, 1972). The aforementioned subtypes of thirst still leave three key outstanding questions which the impulsive-thirst subtype aims to answer:

(i) What causes us to initiate drinking if there is no body water deficit/hypertonicity?

(ii) What determines how much we drink at each drinking occasion?

(iii) What causes us to terminate drinking at each drinking occasion?

In order to answer these questions, a conceptual model from appetite-psychology will be applied to thirst-appetite (see section 3.3.1 for full definitions/explanations of these constructs). Considering food and fluid ingestion are both essential for survival and involve processing by largely the same organs (e.g. the gastrointestinal tract), it seems reasonable that the regulation of both appetites might have similarities that can be drawn upon. Although this is a conceptual model based on psychological constructs, in food-appetite these constructs are regulated neurologically so do have a biological basis. We may have hints towards what the neuro-regulation of these constructs are in thirst, but certainly these ideas warrant thorough testing.

(i) What causes us to initiate drinking? It has previously been suggested that xerostomia may influence drinking behaviours regardless of hydration status (e.g. Brunstrom, 2002; Cannon, 1918; Mayer 1900 cited in Rolls \& Rolls, 1982), but these ideas often get dismissed due to the strong evidence of central thirst. There is, however, no reason why both cannot occur under different circumstances. As such, I propose that ACh is a key (but not unique) regulator of total body water, preventing us achieving regular deficit by causing a (sensation of) dry mouth (and perhaps some related symptoms like dry lips or headache which have not been discussed) which in turn initiates spontaneous or impulsive drinking; thus a (sensation of) dry mouth might be the 'hunger' of body water regulation. The role of ACh as a fluid seeking initiator is supported by evidence that cholinergic stimulation of the lateral hypothalamic produces motivational drinking behaviours similar to water deprivation (Grossman, 1969). These sensations in an everyday context, experientially manifest subtly, particularly when compared to true-thirst and pharmacological-thirst (xerostomia). 
There is also evidence that a dry mouth can influence drinking. Fluid ingestion has been shown to be higher with an artificially-induced dry mouth (cotton-wool rolls in each cheek) (Brustrom et al., 2000); thus the salivary response from fluid ingestion likely provides some form of sensory-specific (oropharyngeal) feedback, determining how much is ingested. As drinking was ad libitum in this study, the results cannot reflect an inhibition of AVP dictating the satiety response, adding weight that this might be moderated in central hedonic pathways, and/or by other factors such as cholinergic activity.

259

(ii) What determines how much we drink at each drinking occasion? With this in mind, it goes to reason that we do not need to drink to full replenishment at each drinking occasion-just as energy balance varies day-to-day, total body water likely has similar variations but on average remains stable. Considering the well-established tight regulation of total body water, it is likely the variation around the average is smaller than compared to energy balance and therefore perhaps is regulated on a shorter time scale (a matter of hours rather than a matter of days, speculatively). It is proposed that palatability (hedonic reward) determines how much is consumed.

(iii) What causes us to terminate drinking at each drinking occasion? There is a wellestablished relatively immediate and temporary (i.e. before physiological changes occur) satiety that occurs upon fluid ingestion (Fitzsimons, 1972); however, this has not been thoroughly operationalised. I propose this phenomenon is sensory-specific satiety (the reduction in hedonic reward to a specific stimulus). Such sensory-specific satiety acts to prevent excessive intake; without a relatively immediate stop-signal (compared to eating), there would be a risk of continued drinking until blood osmolality has returned (Fitzsimons, 1972). By this time too much water would have been ingested resulting in continued reductions in osmolality.

Palatability and sensory-specific satiety are moderated by pleasantness (state liking); i.e. if a stimulus is more pleasant, palatability increases and more is consumed due to a delayed sensory-specific satiety; if something is less pleasant, palatability decreases and sensoryspecific satiety occurs more rapidly, inhibiting intake. There is some evidence for this, for example, findings that drinking is not initiated when there are changes in hydration physiology, but rather due to their ratings of thirst (which may have been mistaken for xerostomia particularly as dry mouth was also measured) and pleasantness of drinking water (Phillips et al., 1984).

Table 3 conceptualises this model in relation to food-appetites. Multiple factors are likely involved in the interplay between sensory-specific satiety and palatability, for example, oropharyngeal sensations such as fluid promoting saliva production (Brunstrom, 2002), a pre-absorptive reduction in AVP (Figaro \& Mack, 1997), and gastric distension (Fitzsimons, 1972) (Figure 2). These factors will likely relay back to dipsogenic regions of the brain which then promote or inhibit drinking (Armstrong \& Kavouras, 2019). Adding to this, in rats, drinking increases central ACh over a variable amount of time $(\sim 20$ minutes to $>90$ minutes) depending on the region (Mark et al., 1992; Rada et al., 2000), thus providing a potential cholinergic mechanism by which the drinking cycle is reset. 
Table 3. Comparison of food-appetites to proposed thirst-appetites, and their role in eating/drinking initiation and inhibition in everyday circumstances

\begin{tabular}{lll}
\hline Food-appetite & Equivalent thirst-appetite* & Role \\
\hline Hunger hormones & $\begin{array}{l}\text { Cholinergic activity (causing true- or } \\
\text { sensational-xerostomia) }\end{array}$ & Initiate eating/drinking \\
$\begin{array}{l}\text { Sensory-specific satiety (\& other } \\
\text { signals, e.g. gastric distension) }\end{array}$ & $\begin{array}{l}\text { Sensory-specific satiety (\& other signals, } \\
\text { e.g. gastric distension, oropharyngeal } \\
\text { sensations) }\end{array}$ & Inhibit eating/drinking \\
$\begin{array}{l}\text { Hedonic reward, desires } \\
\text { (palatability) }\end{array}$ & Hedonic reward, desires (palatability) & $\begin{array}{l}\text { Determine how much is } \\
\text { eaten/drunk }\end{array}$ \\
Satiety hormones & Cholinergic activity, blood osmolality & $\begin{array}{l}\text { Prevent between-meal } \\
\text { eating/excessive drinking }\end{array}$ \\
\hline
\end{tabular}

${ }^{*} A$ range of other factors are also likely involved (Table 4), and these will all relate to some form of neural regulation, as with food appetites

A sensory-specific satiety/palatability approach to thirst appetite can also be evidenced by research showing the pleasantness of the sight and taste of water significantly and meaningful decreases ( $30 \mathrm{~mm}$ reduction on a $100 \mathrm{~mm}$ visual analogue scale) pre- to postwater ingestion (to satiety), despite the taste intensity of the water (also assessed via visual analogue scales) remaining unchanged (Rolls et al., 1983). These findings were specific to fluids (i.e. still occurred strongly albeit to a lesser extent for orange squash), demonstrating that although food and fluid appetites are regulated by different areas of the brain (Rolls et al., 1983), they may be regulated in a similar fashion. Importantly, participants in this experiment were not hypohydrated, demonstrating appetitive effects independent of hydration status. Additionally, the pleasantness of drinks is typically greater at temperatures that maximally stimulate saliva flow (Brunstrom, 2002; Brustrom et al., 1997), providing further evidence to the notion that xerostomia and hedonic reward pathways may regulate fluid ingestion and therefore total body water. Finally, even imagining water in a euhydrated state can activate neurological thirst pathways (Saker et al., 2020), adding weight to waterappetites may have similar types of central regulation to food-appetites. 


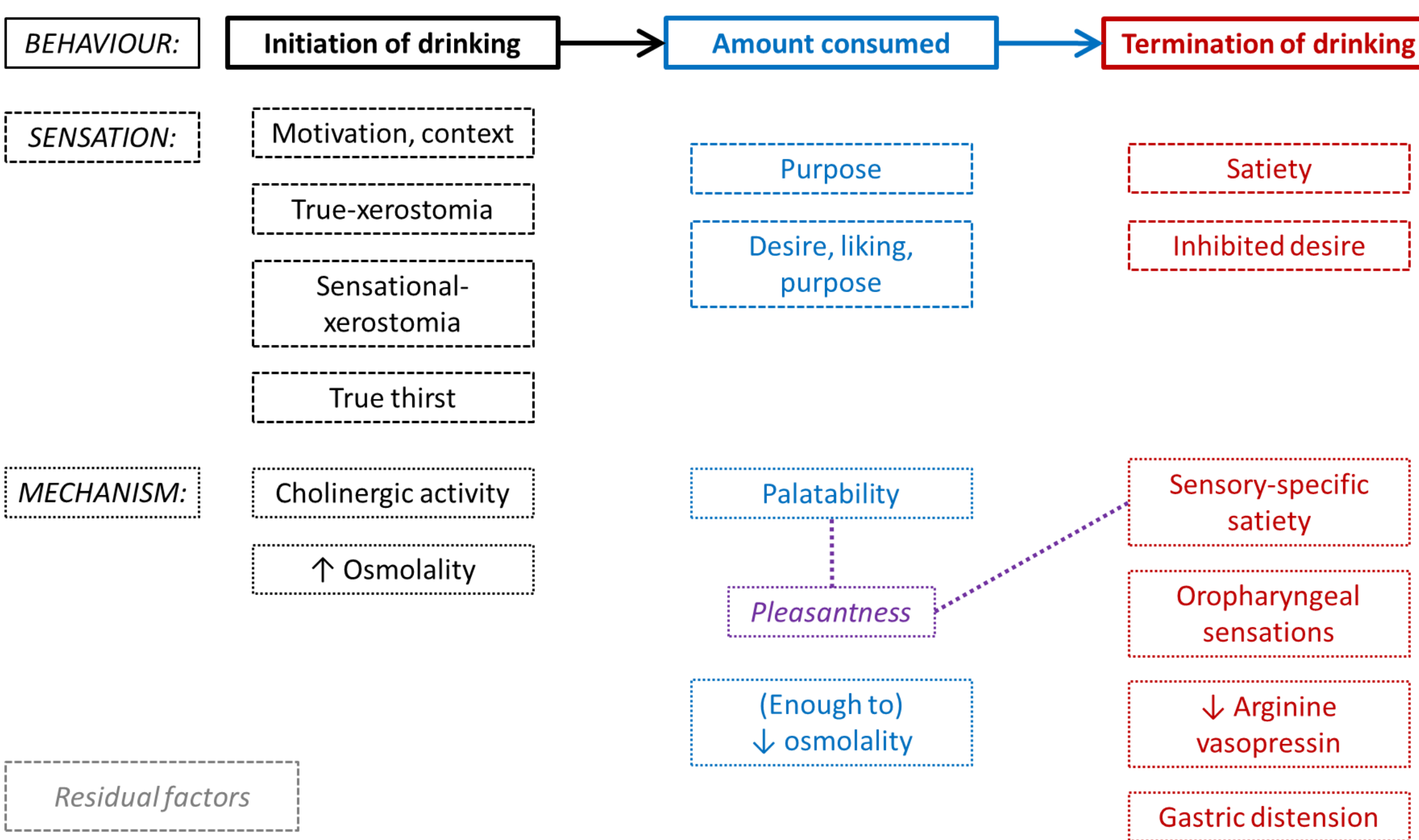

Figure 2. Behaviours of drinking, the sensations that drive these behaviours, and the key mechanisms proposed to regulate these sensations. Mechanisms may be speculatory according to the theory outlined in this thesis. Residual factors include a multitude of other factors which could contribute to each pathway. Pleasantness is a moderating variable between palatability and sensory-specific satiety. 
3 Further details

This section provides additional details and historical context for each type of thirst outlined above (except contextual-thirst which is fully described in section 2.2).

\subsection{True-thirst}

\subsubsection{True-thirst: Further details}

The role of salt and solute ingestion on thirst warrants acknowledgement. The consumption of solutes such as salt in the four-compartment model of thirst I am proposing would constitute as true-thirst as the mechanism to the sensation of thirst is congruent (i.e. an increase in osmolality). Future work may find solute ingestion results in its own subtype of thirst, perhaps based on the neural activation in dipsogenic areas of the brain. Related to salt ingestion is anticipatory-thirst and prandial-thirst, both working via different pathways (Fitzsimons, 1972). In the proposed four-compartment model, anticipatory-thirst would fall primarily under impulsive-thirst (discussed further in section 3.3.3), whereas prandial-thirst would mainly be classed as a contextual-thirst.

\subsubsection{True-thirst: Historical context}

The osmotic regulation of thirst has been known about for over a century. Historically, three competing theories arose: the dry mouth theory; that thirst is 'sensed' across the body; and that thirst is 'sensed' centrally (Fitzsimons, 1972). Much initial research was conducted in the 1800s establishing things like (all citations from both Fitzsimons, 1972, and Rolls \& Rolls, 1982):

- Intravenous infusion of fluids (such as milk or water) relieves thirst in hypohydrated dogs (Dupuytren, cited by Rullier, 1821);

- Patients with excessive thirst can be given intravenous water or saline (Latta, 1832; Magendie, 1823);

- Sham drinking is more effective in stopping drinking in animals than wetting of the mouth (Bernard, 1856);

- Thirst is regulated centrally (Nothnagel [1881] reported a man suffering a head injury from a horse kick, and noted the patient drunk excessively [18.5 L/d], had low urine output, and excessive thirst, concluding that thirst is regulated near the back of the brain, possibly the medulla)

These works implied that thirst is a whole body phenomenon, rather than a sensation of local (oropharyngeal) origin. Thus it was inferred that tissue and/or blood hypohydration was an important factor in thirst, and this may be regulated in the brain.

Subsequently, in 1900, Mayer (cited in Rolls and Rolls, 1982) found a correlation (in dogs) between fluid restriction, plasma hypertonicity, and thirst, followed by Wettendorf finding similar in 1901 (cited in Ramsay, 1989). From these findings, Mayer (1900) concluded that blood hypertonicity increases thirst via excitation of the walls of the vascular system. This excitation then activates receptors in the mouth and throat, resulting in a dry mouth that subsequently drives drinking behaviours. As such Mayer theorised that thirst was due to systemic physiological changes, but drinking behaviour was driven by xerostomia. Thus extracellular osmolality was hypothesised to cause thirst. Conversely, Wettendorf (1901) suggested plasma hypertonicity implicated intracellular hypohydration in thirst (a currently well confirmed finding). 
401

402

403

404

405

406

407

408

409

410

411

412

413

414

415

The pursuit to understand thirst continued by studying saliva flow rate. In 1931, it was found that salivary gland removal does not impact fluid ingestion in dogs (Montgomery, 1931). Additionally, buccal mucosa remained healthy, so it was concluded that salivary glands are not implicated in (canine) thirst regulation. Following this, a man with no salivary glands had relatively typical fluid intake, and would sip water frequently to alleviate the dry mouth and drink larger amounts of water four times a day (Steggerda, 1941). Steggerda (1941) therefore corroborated Montgomery's (1931) conclusion, despite also noting when dry mouth is induced (e.g. by dry heat exposure), fluid ingestion increases by $\sim 45 \%$ above habitual levels.

These findings suggest that thirst is regulated centrally, but also suggests other factors can illicit drinking behaviours, otherwise we would all primarily maintain our body water by relatively infrequent gulping of fluid. Additionally, the evidence provided by Steggerda (1941) demonstrated that a dry mouth did encourage drinking; thus is seems reasonable that factors implicated in xerostomia, such as cholinergic activity, would also encourage fluid ingestion. Finally, these studies suggest that salivary glands per se may not be implicated in thirst or drinking behaviour, leaving other factors (perhaps ACh, sensational-xerostomia, or contextual-thirsts) to explain this gap.

In the 1940s, it was also found that salivary flow rate was correlated with body water losses (Adolph, 1947), directly implicating true-xerostomia with hypohydration. The relationship between hyperosmolality and AVP also became apparent, with hypertonic saline infusion (i.e. drawing water out of cells in the brain) leading to elevations in an osmotically-responsive anti-diuretic hormone originating in the neurohypophysis (pituitary gland), now known as AVP (Verney, 1947). Follow-on studies showed central regulation to be in the hypothalamus, near the supraoptic nucleus (Jewell, 1953; Jewell \& Verney, 1957), and in 1950, Wolf identified osmoreceptors involved in drinking behaviours, including introducing the idea that $\sim 1-2 \%$ fluctuation in osmolality is the threshold for hypertonicity-driven ('true') thirst.

Based off this work, it was found that thirst persisted even when blocking xerostomia sensations (Wolf, 1958, cited in Rolls \& Rolls, 1982), thus leaving hyperosmolality as the dominant model of thirst regulation. Research continued on the osmotic regulation of thirst primarily in the 1970s and 1980s before resurging again more recently. However, the fact that blocking xerostomia does not prevent true-thirst does not preclude xerostomia from being implicated in drinking behaviours in everyday life, where hyperosmolality may not be achieved (Brunstrom, 2002).

\subsection{Pharmacological-thirst}

\subsubsection{Pharmacological-thirst: Further details}

There appears to be a quasi-dose-response and specificity effect in terms of the xerogenic effects of different pharmacological agents. For example:

- Selective serotonin-reuptake inhibitors are less-anti-cholinergic than tricyclic antidepressant drugs, and therefore have lower xerostomia prevalence (Scully, 2003);

- Newer anti-drowsy anti-histamines act via $\mathrm{H} 1$ receptor agonism, rather than sedating the central nervous system which has anti-muscarinic effects, thus reducing xerostomia prevalence (Scully, 2003);

- Muscarinic receptor antagonists can be prescribed for overactive bladders but lack bladder-specificity resulting in increased incidence of xerostomia compared to newer 
incontinence drugs such as tolterodine that are targeted towards the bladder (Scully, 2003)

Thus there appears to be sound mechanistic evidence relating anticholinergic effects to xerostomia. As demonstrated in Figure 1, there is an interaction between true-thirst and xerostomia. Firstly, hyperosmolality (true-thirst) can induce xerostomia. Secondly, true-thirst is regulated by the hypothalamus and the circumventricular organs. Here, we see crossover as these areas receive cholinergic fibres from other brain nuclei and both $\mathrm{mAChR}$ and nAChR are found in these regions (Honda et al., 2003; Ono et al., 2008). Moreover, there is an abundance of $\mathrm{M}_{3} \mathrm{mAChRs}$ in the subfornical organ, a key site of angiotensin II action to illicit drinking (Simpson \& Routtenberg, 1973), creating a further link to hormones we more typically consider as regulating body water.

Finally, in terms of distinguishing true- and sensational-xerostomia, Inengaga \& Ono (2010), provide valuable perspective based on work in their lab. Intraperitoneally administered pilocarpine (a muscarinic agonists and sialogue) in rats resulted in an increased intake of water; in other words, the rats felt thirsty despite having a wet mouth. Conversely, intracerebroventricular administration induced drinking but not saliva secretion, as the drug could not cross the blood-brain barrier into general circulation to impact the saliva glands. This somewhat goes against the classic 'true-thirst' model which dictates thirst is solely regulated centrally, but does add weight to the proposal that true- and sensationalxerostomia may need differentiation. Overall these data and ideas suggest that thirst is regulated by hormonal, physiological, and neuronal inputs (Fitzsimons, 1972; Inenaga \& Ono, 2010), perhaps demonstrating the need for a systems approach to its regulation.

\subsubsection{Pharmacological-thirst: Historical context}

Cholinergic thirst is not a new idea. Acetylcholine was known about in the early 1900s. It was possibly first linked to saliva production in animals in 1913 by Demoor (cited in Alles, 1934), however Fraser (1938) cited Villaret and Justin-Besançon (1928) as the first to report the action of ACh in humans. In a 1932 study noted by Fraser (1938), Ellis and Weiss intravenously administered ACh reporting flushing of the head, sweating, lacrimation, and salivation, among other symptoms. Similar work was also reported in 1932, confirming the role of ACh and the cholinergic system in saliva production (Babkin et al., 1932; Henderson \& Roepke, 1932, 1933; Gibbs \& Szelöczey, 1932, all cited in Gaddum, 1935). Through the early 1900s, it was also known that certain drugs could inhibit or amplify the effects of ACh such as atropine, and physostigmine, respectively, including the ability of atropine to inhibit saliva production (Fraser, 1938).

In the 1960s there appeared to be a resurgence in interest in the role of the cholinergic system in thirst and saliva production. Grossman (1960) found intra-hypothalamic infusion of ACh or carbachol (an ACh receptor agonist) in the rat brain increased drinking compared to epinephrine, norepinephrine and saline, concluding that thirst is mediated by the neurological cholinergic system. Atropine (an anticholinergic drug) is known to reduce saliva production and induce xerostomia by blocking mAChRs (Levitt, 1969), however, it is unclear whether it increases (Chapman \& Epstein, 1970) or decreases (Levitt \& Fisher, 1966; Schmidt et al., 1958) fluid intake. The response may be moderated by food intake (Chapman \& Epstein, 1970), having implications for (contextual) prandial-thirst.

Subsequently it was reported that lesions in cholinergic areas of rat brains (particularly the septal area of the forebrain) reduced ACh by $\sim 20 \%$ and increased water intake by $\sim 50 \%$, 
467 implicating ACh in drinking behaviours (Sorensen \& Harvey, 1971). Such findings were

468 supported by comparing non-hyperdipsic rats who had no decrease in ACh to hyperdipsic

469 rats who had a $35 \%$ reduction in ACh in the brain $(r=-0.73$ for reduction in ACh versus

470 increase in water intake) (Sorensen \& Harvey, 1971). Further, research in rats demonstrated

471 drinking behaviours in response to osmolality or plasma volume changes may be mediated

472 by cholinergic (and catecholaminergic) pathways (Block \& Fisher, 1975).

More specifically, the subfornical organ was subsequently implicated in cholinergic thirst via exogenous administration of ACh which elicited drinking in rats (Grossman, 1969; Mangiapane \& Simpson, 1983; Simpson \& Routtenberg, 1974). This was an important finding relating to our classic model of ('true') thirst as the subfornical region is heavily implicated in angiotensin-induced thirst and drinking behaviours, and therefore may help explain the moderating effect of food intake described above. Whilst Simpson and Routtenberg (1974) concluded the interaction between subfornical organ cholinergic and angiotensin thirsts should be explored, to my knowledge this has not been thoroughly examined (sentiments also shared by Fitzsimons in 1972).

Taken together, Blass and Chapman (1971) proposed that the cholinergic system has a partial but important contribution to thirst, driven by ACh. These effects are reliable and impact drinking behaviours across a variety of different methods of dehydration (Block \& Fisher, 1975). Importantly, they acknowledge the role of osmotic and hormonal thirst, echoing earlier statements from Levitt and Fisher (1966) who stated osmotically-induced thirst was triggered during deprivation thus does not necessarily address the entirety of drinking behaviours.

491

492

493

The discordances with the research presented above may provide useful information into the specificity of cholinergic thirst. Firstly, exogenous administration of ACh or carbachol into the subfornical organ (a well-established dipsogenic region) reliably elicits drinking; however lesions in the forebrain (which reduce cholinergic activity) also elicit drinking. It may therefore be that different areas of the brain induce a different drinking or thirst response (Grossman, 1969). Alternatively or additionally, it may be that responses are context-specific; in other words, reverse logic does not apply when comparing responses from lesions in the brain to exogenous stimulation.

500

501

These mixed findings may also be indicative of the interactions between different thirst subtypes (and the residual factors not accounted for herein). It may be that anticholinergic effects cause a dry mouth and reduce drinking, whereas cholinergic stimulation causes saliva production and drinking. This instinctively may seem counterintuitive in that a dry mouth should cause an increase in drinking. However, these experiments are highly controlled and in animals. In humans, for example taking anticholinergic drugs resulting in true-xerostomia, other mechanisms may intercept the anticholinergic response and instead encourage drinking. In a very basic and controlled model in rats, carbachol-stimulated drinking was terminated from gastric distension, rather than satiation or a reduction in thirst (Quartermain \& Miller, 1966). These results, albeit rather crudely provide evidence for other regulatory mechanisms and feedback loops which may override cholinergic signalling.

512

Following this line of thought, a final proposed possibility for humans is that there is specificity to the anticholinergic effects of drugs. For example, these drugs may have differential local and central effects in terms of altering drinking behaviours (Grossman, 1969), and this may be partially dependent on whether the drug in question can cross the blood-brain-barrier, as per the rat experiments described by Grossman (1969) and Inenaga 
518 and Ono (2010). Overall, the pharmacological-induced cholinergic-thirst provides an

519 important step towards understanding thirst regulation, though research into the real world applicability and nuance of this thirst subtype in humans is unclear.

\subsection{Impulsive-thirst}

525

\subsubsection{Impulsive-thirst: Further details—hedonic rewards}

With food-appetite, we do not wait until we are nutrient-deficient in order for hunger to be

526

527 triggered. Equally, satiety is not solely driven by nutrient repletion either. For example, carbohydrates suppress ghrelin-induced hunger most effectively, whilst fat suppresses it most weakly, despite being the most energy-dense nutrient (Cummings, 2006). Similarly, satiety can occur via non-nutrient-specific pathways, such as gastric distension (Wang et al., 2008), thus is not solely the result of nutrient repletion. Therefore, this a food-appetite model can perhaps explain why we can drink (or not drink), regardless of our actual hydration status.

Additionally, food-appetite is not entirely regulated by the hunger-fullness centres of the brain, nor solely by hunger-fullness hormones (such as ghrelin or glucagon-like peptide-1) or sensations (such as gastric distension); reward pathways play an important role in appetite control. Whilst reward pathways are neurological and physiological, they present as psychological constructs ('desire', 'liking', 'motivation to consume', etc).

540

541

542

543

544

Two key neurologically-driven psychological constructs of food-appetite are sensory-specific satiety and palatability. Sensory-specific satiety is the rapid reduction in the pleasantness (hedonic reward) of a food, typically occurring within two minutes of eating and does not apply to foods that are not being eaten (Heatherington et al., 1989; Rolls et al., 1981; Rolls, 1986). From an evolutionary perspective, this has been hypothesised to maximise nutrient intake by ensuring a wide range of foods are eaten (Rolls, 1986). In terms of fluid ingestion, speculatively, two evolutionary perspectives come to mind with regard to drink-induced sensory-specific satiety. Firstly, subtle physiological cues (i.e. not the overwhelming cues that arise from true-thirst) to drink regularly may provide maximal absorption and therefore maintain body water more efficiently as large boluses of water are known to suppress AVP (Enhörning et al., 2019a); and secondly, frequent drinking may encourage drinking from different sources where possible, therefore reducing the chance of consuming large quantities of potentially contaminated water.

553

554

555

556

557

558

559

560

561

562

563

564

565

566

567
Sensory-specific satiety is not driven by changes in taste intensity (Yaxley et al., 1985; Rolls et al., 1988), nor is it related to postabsorptive physiological changes occurring from nutrient intake (Rolls, 1986; Rolls \& Rolls, 1997; Sorensen et al., 2003). Additionally, once a new food is introduced, the 'system' resets (Rolls et al., 1984), perhaps providing evidence as to why we can drink different types of drink beyond our physiological needs. Considering there is tentative evidence of water taste receptors (Zocchi et al., 2017), and of water increasing activity of the chorda tympani (Liljestrand \& Zotterman, 1954), it can be tested whether objective taste intensity decreases with exposure and therefore whether this food-appetite construct can indeed be applied to thirst-appetites.

On the other hand, palatability is the hedonic reward from a food (Guyenet \& Schwartz, 2012). Palatability therefore drives consumption, even beyond satiety (Yeomans et al., 2004), broadly working antagonistically with sensory-specific satiety. Pausing within a palatable meal increases energy intake (Yeomans et al., 1997) potentially suggesting a 
'resetting' of the counter-regulatory sensory-specific satiety response. This fits with the evolutionary perspective posited for sensory-specific satiety, as it psychologically allows being around a single source of water for a prolonged period whilst still enabling drinking to mitigate hypohydration. Palatability can also be conditioned upon repeated exposure, to either increase (Anguah et al., 2017; Gonzalez et al., 2018) or decrease (Siegel \& Pilgrim, 1958) desire, depending on baseline pleasantness.

Pleasantness is essentially (state) liking, encompassing the niceness of the oral sensations in the mouth, such as taste, rather than the pleasantness of actual ingestion (which is more akin to palatability) (Rogers \& Hardmen, 2015). Vickers (1988) showed that when participants found lemonade (sweetness level) less pleasant, they consumed less of it; in other words, they achieved sensory-specific satiety more quickly. Equally, when pleasantness was rated higher, little or no sensory-specific satiety occurred. These hedonic reward constructs where therefore applied to the impulsive-thirst subtype.

Such a model may be useful for explaining certain observations pertaining to everyday drinking behaviours, for example:

(i) Post-exercise, a large bolus of fluid is typically consumed quite rapidly, followed by regular sipping. In this instance, pleasantness of fluid may have increased, resulting in higher palatability which inhibits sensory-specific satiety (Rolls et al., 1990). This of course interacts in at least some circumstances with true-thirst (Figure 1)

(ii) Why cooler/hotter drinks are often preferred over room temperature/tepid drinks (Brunstrom, 2002). In this instance pleasantness increases, and this may additionally be driven by the increased salivation that occurs at these temperatures (Brunstrom, 2002), providing a link back to xerostomia

(iii) Perhaps explains why we can drink the same drinks multiples times across the day everyday (i.e. resetting of sensory-specific satiety of a palatable drink), as well as individual preferences in beverage choice

(iv) Perhaps also the interaction between food and fluid appetites; the flavour of drinks may increase food-related palatability, but the mode of ingesting this flavour (i.e. via fluid) does not trigger food satiety cues

In relation to (i), post-exercise drinking behaviours appear to demonstrate that the osmoregulatory intake of fluids is controlled in such a way as to return the body to a roughly euhydrated state (Rolls et al., 1990). Thus it seems likely other factors play a role in everyday drinking behaviours where fluid ingestion often exceeds immediate water needs (i.e. there is no deficit to be compensated for).

With regard to (iv) (albeit somewhat debatably), drinking satiates thirst, but does not appear to satiate hunger, even when the drink contains energy. Typically, thirst-satiating drinks are cold, hot, or acidic (all of which encourage saliva production), and these drinks may contain energy (e.g. sugar-sweetened beverages) (Brunstrom, 2002). Thus, such signals may be detected more so in the thirst centre of the brain rather than the hunger-fullness centre of the brain, potentially explaining why liquid energy may be incompletely compensated for (Allison, 2014).

\subsubsection{Impulsive-thirst: Further details-habits}

Speculatively, a large proportion of our drinking is probably habitual. Some biological instincts likely help create some of these habits, such as anticipatory- and/or prandial thirst. Whilst habitual intake has been classed as a contextual-thirst, the formation of habits and 
619 how we regulate our thirst outside of habitual situations may (at least partially) be explained

620 by the constructs described in impulsive-thirst.

621

622

623

624

625

626

627

628

629

630

631

632

633

634

635

636

637

638

639

640

641

642

643

644

645

646

647

648

649

650

651

652

653

654

655

656

657

658

659

660

661

662

663

664

665

666

667

668

669

A habit is a behaviour that is repeated, automatic, and context-cued (Wood \& Rünger, 2016). An automatic behaviour is one that requires minimal awareness, has lack of conscious intent, is difficult to control, and is mentally efficient (Bargh, 1994). For example, whilst travelling (lack of context-cue), fluid has to be actively sought after (lack of automaticity and repetition). It is unlikely that in all cases of travelling this fluid-seeking behaviour is due to osmotically-driven true-thirst, or that it fulfils another desire such as the desire for caffeine. In this instance, I propose that the cholinergic system first alerts a person to seek fluid, then other appetite signals (sensory-specific satiety and palatability) determine how much is consumed.

In the context of real-life, the true-thirst model would mean we would not have low- and highfluid consumers (Perrier et al., 2013); low water drinkers should be chronically thirsty and this should drive them to consume more fluid; equally, it is unclear as to why some people continue drinking beyond their needs to maintain euhydration. These differences have not been adequately explained. As with food appetite which demonstrates high variance (from anorexia nervosa to obesity with a range of interacting aetiologies, e.g. Government Office for Science, 2007), the differences between low and high fluid consumers are expected to be manifold and complex.

Additionally, it is possible that some form of pleasantness-induced habit (likely developed during early life and childhood [e.g. Rosinger, 2019], as food preferences do; Cooke \& Fildes, 2011) either (i) changed the physiological response to thirst; or (ii) altered sensitivity to thirst signals. For the former idea (i), it may be that responses such as ACh adapt to lower fluid intake, meaning thirst and xerostomia are not experienced as intensely. Analogous changes in physiology are feasible in this manner, for example, timing of eating can alter pancreatic $\beta$-cell sensitivity (Morris et al., 2015), or food can entrain anticipatory circadian rhythms (Mistlberger, 2011).

For the latter idea (ii), it may be that low fluid drinkers do have the same (hypothetically) objective level of thirst, but are less sensitive to it so respond much later. In this instance, I would propose that they might be less sensitive to ACh, so perhaps do wait until true (osmotically-driven) thirst occurs. Analogous changes in sensitivity in other contexts do also occur, for example, food reward is lower in those with obesity (Herrera Moro Chao et al., 2016), and in the context of thirst, ageing disrupts typical thirst responses (Stout et al., 1999). Thus, a combination of early-life exposures/experiences, baseline palatability, and physiological adaptive responses (and probably other factors), all combine to create initial drinking habits, resulting in high- and low-fluid consumers who drink despite their hydration physiology.

In terms of changing habits, again this will likely be regulated by many factors, with probably a triggering event leading to the initial change, as per the habit discontinuity hypothesis (for example, a disease diagnosis, or a change in physical activity) (Verplanken \& Roy, 2016). As with habit formation, this habit change may lead to changes in physiology and/or sensitivity. Considering the difficulty of habit change, as with food-appetite where only a small proportion of people are successful at changing their diet due to a range of environmental, physiological and psychological reasons, there are likely similar difficulties with thirst-appetite changes. 


\subsubsection{Impulsive-thirst: Historical context}

Previous research has proposed the idea of anticipatory-thirst. The theory outlined above does not dispute this concept; rather the two are quite complimentary. In the impulsive-thirst model outlined above, I propose anticipatory-thirst to be (at least partly) driven by cholinergic activity, and then the psychological aspects of appetite to determine the amount consumed, with synergistic input from known anticipatory-thirst signals.

The reason anticipatory-thirst has been designated as a subtype of impulsive-thirst, is that anticipatory-thirst implies some form of impending deficit, whereas the model outlined above requires no (impending) deficit, and could even work in a model of excess (discussed further in sections 4.2 and 4.4). Since anticipatory-thirst is 'triggered' pre-emptively to avoid hypertonicity, it has not been classed as true-thirst. Key areas where impulsive and anticipatory-thirst differ include:

685

686

687

688

689

690

691

- Anticipatory-thirst being triggered by hydration-related physiological changes, such as an increase in core body temperature, food intake, and/or diurnal rhythms (Gizowski \& Bourque, 2018)

- Anticipatory-thirst predicts osmotic challenges and therefore triggers thirst as a response to that (Watts, 2017). This has been likened to cephalic phase responses (Watts, 2017); however, cephalic phase responses mitigate abnormal responses (e.g. hyperglycaemia in the case of the cephalic phase insulin response), whereas impulsive-thirst has no intended physiological effect

- Anticipatory-thirst describes the neural pathways in which thirst is mitigated upon ingestion (Bichet, 2018), but offers no explanation as to why this occurs, and therefore in some ways precludes being testable in humans. Such a neural response may be related to palatability/sensory-specific satiety which should be tested

- Anticipatory-thirst does not explain situations of hyperhydration, hyponatraemia, and excessive thirst, nor why we do not wake up during sleep to drink (whilst not discussed further, the cholinergic system is active during sleep, and this activity reduces during light wakefulness [Watson et al., 2010], potentially explaining why we typically do not wake up due to true-xerostomia mid-sleep, and perhaps explaining the morning dry mouth commonly experienced upon waking?)

- There remain some contradictions, for example, anticipatory-thirst demonstrates a preprandial elevation in AVP and thirst in order to maintain blood osmolality (by not excreting water during an osmotic challenge) (Watts, 2017). Concurrently, prandial drinking occurs which in theory would suppress AVP (and therefore thirst?) (Watts, 2017). Thus other mechanisms must aid in water balance beyond osmolality and AVP. This is further supported by anticipatory-thirst being tested in highly controlled animal models which often have a behavioural or circadian 'cue' (e.g. Gizowski et al., 2016; Mandelblat-Cerf et al., 2017); thus how does anticipatory-thirst work outside of habitual contexts?

- Anticipatory-thirst does not fully explain why the pleasantness of the taste and sight of water decreases after consumption, but the intensity of the taste does not (Rolls et al., 1983); rather, this immediate reduction in reward/consumption would mitigate the purpose of anticipatory-thirst

- Neither anticipatory thirst, nor true-thirst explain post-hypohydration rehydration patterns, frequently consisting of a large immediate bolus of fluid, followed by intermittent intakes of small quantities of fluid even after hydration status has recovered (Rolls et al., 1980). This intermittent drinking has been reportedly due to unpleasant mouth sensations (Rolls et al., 1980) (which may be explained by psychological appetite constructs like pleasantness and/or ACh) 
722 Nonetheless, anticipatory- and impulsive-thirst do overlap, as with other thirst appetites

723 proposed (Figure 1). For example, cholinergic thirst acts on the subfornical organ (Simpson

724 \& Routtenberg, 1974), as anticipatory-thirst does (Bichet, 2018). As such, I propose that

725 anticipatory thirst is a type of impulsive-thirst, and this relationship and categorisation

726 warrants further investigation and validation. 


\section{Theoretical evidence and application}

In order to evaluate the likelihood of the four-compartment model presented above giving at least a fuller (albeit likely still incomplete) representation of thirst regulation, current anomalies in thirst and drinking behaviour are presented below. Anomalies in this instance are defined as situations in which the classic 'true-thirst' model does not adequately explain the desire to drink. Rather, I hypothesise that many anomalous examples of thirst (dys)regulation are a result instead of ACh dysregulation (of sorts), or currently unknown aetiologies.

The below are select examples because there is something particularly unique about the type of thirst they induce (for example, hypotonicity and high thirst). However, several other examples are available demonstrating xerostomia and/or increased thirst independent of actual hydration status. Similar to the examples below, these also interfere with cholinergic activity and cause thirst/dry mouth and may therefore result in drinking behaviours and subsequent changes in hydration physiology; for example, cannabis use (Grotenhermen \& Müller-Vahl, 2012; Mangot, 2013), nicotine use (Inenaga \& Ono, 2010), and Sjögren's syndrome (Ono et al., 2004; Sumida et al., 2013). Of course, the below are hypotheses to explain current anomalies, and could indeed be incorrect; as such, they are presented as particularly unique cases worthy of researching further.

\subsection{Ageing}

Ageing provides a distinct model of hydration physiology, in part because it is natural (i.e. not induced by behavioural/pharmacological activities), and in part because it does not fit our current osmoregulatory model of thirst. In older adults, it is not uncommon for seemingly contradictory things to co-occur in terms of hydration physiology:

- Reduced saliva production (Meyer \& Necheles, 1940) and therefore increased truexerostomia yet lower sensitivity/responsiveness to thirst (O'Neill \& McLean, 1992; Phillips et al., 1993; Ramsay, 1989)

- Hypertonicity, but low fluid intake (Kenney \& Chiu, 2001; Phillips et al., 1993)

- Low urine output (due to low fluid intake/high circulating AVP concentrations) but low urine osmolality (due to reduced concentrating capacity of the kidneys) (O'Neill \& McLean, 1992; Stout et al., 1999)

- Reduced ability to excrete urine additionally increases risk of hyponatraemia, despite simultaneous high risk of hypertonicity (Rolls \& Phillips, 1990)

- Greater AVP sensitivity/responsivity to blood osmolality (Davies et al., 1995)

This differentiation in hydration physiology between younger and older adults is important to understand holistically as dysregulated hydration physiology is associated with higher mortality in older adults (Stout et al., 1999). Considering the atypical physiology, it is unclear why there is a thirst deficit (Rolls \& Phillips, 1990). Several theories have been posited in the literature, and likely each have an important role. For example, diminished baroreceptor sensitivity with regards to reduced extracellular volume in response to hypertonicity (Kenney \& Chiu, 2001; Phillips et al., 1993); reduced sensitivity of oropharyngeal sensors to fluid (Phillips et al., 1993); loss of AVP circadian rhythmicity (Miller, 2015); decreased reninangiotensin-aldosterone activity (Miller, 2015); increased atrial natriuretic hormone (Miller, 2015); and/or age-related neuroendocrine changes (Rolls \& Phillips, 1990).

Another pathway could be the cholinergic system. Ageing reduces ACh synthesis and release, thus reducing cholinergic activity (Gibson \& Peterson, 1981). This is a strong 
phenomenon: age-related degeneration of cholinergic neurons in the brain are associated with Alzheimer's disease, with nicotine (which acts on nAChRs) having a neuroprotective role (Muir, 1997; Zanardi et al., 2002). To my knowledge, there is no research directly relating ageing, cholinergic activity, and thirst regulation. By inference, and according to the theory I posited above, since ageing reduces ACh synthesis and release, both truexerostomia would manifest (from a reduction in salivary gland ACh agonism) with a concurrent decrease in drinking (from a reduction in central ACh activity, particularly in dipsogenic regions of the brain).

As such, cholinergic thirst may explain some anomalies with age-related hydration physiology. Additionally, muscarinic receptor antagonists are used in the treatment of overactive bladder (Scully, 2003); yet urine frequency appears to either not change (Burgio et al., 1991) or increase (Miller, 2015) with ageing. Thus, the age-related reduction of cholinergic activity either does not affect the bladder, or other age-related factors override any anticholinergic effects on the bladder (reviewed in Miller, 2015). Perhaps an alternative perspective could be that considering the typically lower urine output, no change in urine frequency may equate to a relative increase in bladder activity, perhaps representing the reduction in cholinergic activity. Moreover, as ACh is a key neurotransmitter at the neuromuscular junction, depletion with age potentially adds a further barrier on top of a multitude of other difficulties with regards to the physical demand of drinking more and going to the toilet.

There may also be hedonic appetite changes which make drinking less desirable, for example, taste perception decreases with age (Methven et al., 2012). Whilst with foodappetite a reduction in taste perception may result in polyphagia (e.g. Herrera Moro Chao et al., 2016), it is unknown whether the same conclusion could be made for water-appetites, or whether the context of ageing moderates this relationship particularly considering undernutrition is a concern in older adults. Overall, cholinergic dysregulation in ageing may help explain some of the anomalies in age-related hydration physiology and regulation, such as the typically lower fluid ingestion.

\section{2 (Endurance) Exercise}

During exercise, xerostomia is likely to occur due to environmental factors, namely mouthbreathing, and this may be moderated by temperature and humidity. Of course, exercise does also deplete total body water, and true-thirst can occur interacting with the aforementioned thirst appetites. True-thirst will typically occur after the desire to drink has commenced though, and does not explain why (endurance) athletes can continue drinking even with hyponatraemia (Almond et al., 2005). Accordingly, hyperosmolality cannot be the stimulus for (continued) drinking (therefore exercise-induced hyponatraemia-thirst is somewhat akin to pathological thirst). Further, at least in some cases, it is likely that fluid ingestion occurred before major shifts in osmolality from body water losses, therefore opening the question of why the athletes started drinking to begin with. Sensationalxerostomia during exercise may be an independent factor working beyond contextualenvironmental-thirst such as mouth-breathing or (if applicable) true-thirst. Experientially, drinking does not appear to satiate this athletic-thirst.

Choline is an essential nutrient, with only insufficient amounts being synthesised endogenously by the liver, the primary organ for its metabolism (Corbin \& Zeisel, 2012). Choline is implicated in multiple physiological process, including ACh synthesis. Strenuous exercise such as marathons appear to deplete circulating choline concentrations and reduce 
performance (Penry \& Manore, 2008). The drop in circulating choline has been posited to be due to an increased need for choline as a methyl-group donor (Kanter \& Williams, 1995). Consequently, there is lower choline availability for ACh synthesis (Conlay et al., 1992). In addition, compartmental shifts in body water may interfere with measures of circulating concentrations of choline as free choline gets dissolved in interstitial fluid (Penry \& Manore, 2008), thus reducing choline availability and further limiting ACh synthesis.

As such, (endurance) exercise-induced polydipsia may in part be due to dysregulated cholinergic activity. The consequence of this response may depend on local or central effects of exercise on cholinergic activity (Fitzsimons, 1972) and how this interacts with psychological thirst-appetite constructs:

(i) Extended activity may deplete local ACh (for non-essential functions such as saliva production) in order prioritise neuromuscular activity, thus cause truexerostomia. This may increase the pleasantness of fluid, resulting in higher palatability and an inhibition of sensory-specific satiety (Ali et al., 2011; Appleton, 2005), therefore causing excessive drinking

(ii) Extended activity might increase cholinergic activity at receptor sites (thus circulating ACh might appear low), and if central ACh activity increases, excessive drinking occurs. This may be exacerbated by inhibition of sensoryspecific satiety from increased palatability

(iii) Extended activity may deplete both local and central ACh, resulting in true- but not sensational-xerostomia; as with (i), true-xerostomia may increase pleasantness and increase drinking, regardless of central cholinergic signals

Whilst supplementing with choline appears to have no or minimal performance benefit (Penry \& Manore, 2008), studies should investigate choline supplementation in endurance athletes in relation to their drinking behaviours and total body water balance. Whilst multiple factors are involved in exercise-induced polydipsia, I am proposing that dysregulation of the cholinergic system potentially has an important role, notwithstanding interactions between contextual-environmental-thirst (including perceptions that drinking regularly is a necessity) and true-thirst, as well as the role of hedonic appetite constructs.

\subsection{Alcohol hangovers}

From a hydration perspective, alcohol is an interesting drug as it in some ways queries conventional hydration physiology. After acute alcohol ingestion in chronic users (i.e. those who have an alcohol addiction), serum osmolality increased, whilst AVP was suppressed (Collins et al., 1992). Moreover, urine output following alcohol ingestion was significantly lower than controls (those without alcohol addiction). Prior to the alcohol challenge, plasma renin activity, aldosterone, and angiotensin II were similar between groups; post-ingestion, only angiotensin II was elevated compared to controls. Post-alcohol ingestion, no difference in thirst was found between the two groups, despite higher thirst pre-alcohol ingestion in those with alcohol addictions (Collins et al., 1992). Although a model of health cannot be inferred from those with alcohol addictions, this does provide evidence that thirst and body water homeostasis are not solely regulated by osmolality, AVP, or the renin-angiotensinaldosterone system, thus making alcohol an interesting case to advance thirst research.

A prevalent, though as yet unfounded, belief is that alcohol-induced hangovers are caused by hypohydration (Lemon, 1993). This thought is primarily driven by the diuretic effect from AVP suppression that occurs with alcohol ingestion. However, there is currently no evidence 
suggesting alcohol-containing beverages cause hypohydration. I propose that this is unlikely on many counts, including that:

- The amount of water co-consumed is enough to counteract any diuretic losses in body water (Hobson \& Maughan, 2010; Maughan et al., 2016)

- There is no correlation between hangover severity and AVP concentrations (Penning et al., 2010);

- Alcohol may even raise serum osmolality (particularly after hypohydration; Hobson \& Maughan, 2010) potentially driving water retention rather than loss;

- Water losses would likely be minimal (likely less than a moderate exercise);

- Salty food is (anecdotally) commonly consumed before/during/after alcohol ingestion which would mitigate the diuretic effect by stimulating AVP;

- The late phase of alcohol ingestion shifts from having a diuretic to an antidiuretic effect (Inenago et al., 2017; Taivainen et al., 1995)

- Anecdotally there does not appear to be a difference in hangover symptoms when people consume the equivalent amount of alcohol via spirits alone versus spirits plus mixer (though this of course should be tested)

Further research does need to be conducted however, particularly for higher concentration alcohol-containing beverages and binge-drinking.

Despite the above, and notwithstanding the need for well-controlled research on this topic, the perception that alcohol causes dehydration probably persists at least in part because of the dry mouth and other (perceived) hydration-related symptoms (e.g. headache) during the hangover (Howland et al., 2013). To my knowledge, there is no direct evidence systematically testing this, but it seems unlikely for the aforementioned reasons. The most likely candidate for the hangover xerostomia is acetaldehyde which influences the reninangiotensin-aldosterone system, the dipsogenic centre in the brain, and several other thirstrelated pathways (reviewed in Inenaga et al., 2017). The increase in drinking may be a function of the toxicity of acetaldehyde and the need for this to be diluted (Inanaga et al., 2017). However, other mechanisms may additionally be involved.

Alcohol is typically a depressant drug acting on multiple systems, such being an agonist to the gamma aminobutyric acid system (which may also be implicated in thirst; see Table 4). Alcohol also binds directly to ACh receptors and increases extracellular ACh concentrations in the ventral tegmental area in the brain (Feduccia et al., 2012; Larrson et al., 2005). The increase in (central) ACh with alcohol ingestion might explain why alcohol-binge drinking can occur without reaching satiety (as per Quartermain \& Miller, 1966). These effects are during alcohol consumption/within the time frame for its metabolism, and so do not answer questions regarding the hangover phase. The ACh response during the hangover phase appears untested, but might depend on whether cholinergic activity remains elevated, or whether there is a compensatory reduction in activity (and where the increase/decrease in activity is):

(i) In rats, high alcohol concentrations cause ACh accumulation in the brain (Parker et al., 1978). If this accumulation continues during the hangover phase, this may account for the headache/migraine-like symptoms (Kunkle, 1959) that typically occur with a hangover, and sensational-xerostomia, resulting in (desire for) fluid consumption

(ii) If the central accumulation of ACh described in (i) resulted in a reduction in peripheral $\mathrm{ACh}$, particularly at salivary glands, this could result in truexerostomia, whilst simultaneously giving a sensational-xerostomia (as central ACh is elevated), both of which may encourage drinking 
(iii) If there is a central compensatory decrease of ACh during the hangover phase, this would not facilitate fluid ingestion, meaning other mechanisms are more likely implicated

(iv) If there is a peripheral decrease in ACh, as with (ii), this may cause truexerostomia which may encourage drinking

(v) As alcohol acts on central reward pathways, there may be some (perhaps dysregulated) hedonic appetite constructs involved, such as increased palatability of fluid.

Of these hypotheses, it speculatively seems most likely that (iii) and (iv) will be the correct cholinergic responses. This prediction is based on hepatic choline synthesis during alcohol use. Choline is essential for liver health (Corbin \& Zeisel, 2012), and alcohol detrimentally affects hepatic choline metabolism (Zeisel, 2011). Thus, it may be that the increase in central ACh during alcohol use depletes circulating/stored choline, whilst simultaneously increasing hepatic demand. As such, it is therefore possible that alcohol use increases cholinergic activity causing a depletion of hepatic choline stores, resulting in a reduction in cholinergic activity through the hangover period. I was unable to find studies testing whether choline supplementation prior to commencing alcohol ingestion could help reduce hangover symptoms such as xerostomia. Notably though, several hangover cure patents involving choline were found during this search. It is also noted that eating is often purported to help mitigate some hangover symptoms; part of this may be due to hepatic choline repletion, particularly as higher protein foods (which typically have higher choline content) are often selected during hangovers, compared to after alcohol abstinence (Kruger et al., 2018). Accordingly, the effect of alcohol ingestion and resulting hangover symptoms on ACh should be tested in the future.

\subsection{3,4-Methylenedioxymethamphetamine}

Of any drug, 3,4-methylenedioxymethamphetamine (MDMA) is the most fascinating in terms of its effects on hydration physiology. In brief, MDMA causes an elevation in AVP, resulting in increased urinary concentration and low urine volume, whilst simultaneously causing hyperhydration (with mixed results showing either no change in plasma osmolality or hyponatraemia) (Carroll \& James, 2019). The hyperhydrating effects of MDMA are potent enough to be a leading cause of injury and death in users (Rosenson et al., 2007), and intake of fluid does not appear to suppress AVP (Brvar et al., 2004) as would be expected when AVP is elevated (Enhörning et al., 2019b). One reason for the hyperhydration risk is that thirst is elevated during MDMA use (akin to pathological thirst), causing users to drink excessively whilst simultaneously retaining surplus body water (Scully, 2003).

Thus, MDMA does not fit the true-thirst model because total body water is increased rather than in deficit with either normal- or hypoosmolality, yet thirst is increased (similar to exercise-induced polydipsia with hyponatraemia). Accordingly, there are two potential explanations that could describe the effects of MDMA on basic hydration physiology and thirst:

(i) Hyperhydration dilutes salt concentrations across the body explaining the risk of hyponatraemia (i.e. hypotonicity; as per Baggott et al. [2016], Brvar et al. [2004], and Wolff et al. [2006]) but not explaining the intense experience of thirst;

(ii) Blood osmolality remains unchanged (as per Henry et al. [1998], and Simmler et al. [2011]) perhaps drawing salt from other compartments to account for the higher blood volume, neither explaining the increase in thirst nor the elevated risk of hyponatraemia 
980

981

982

983

984

985

986

987

988

989

990

991

992

993

994

995

996

997

998

999

1000

1001

1002

1003

1004

1005

1006

1007

1008

1009

1010

1011

1012

1013

1014

1015

1016

1017

1018

1019

1020

1021

1022

1023

1024

1025

1026

1027
It may be that both of these hypotheses are correct, but (i) only occurs if an extreme excess of fluid is ingested. Since in both cases AVP is elevated, this may suggest AVP regulates thirst rather than osmolality (or at least in certain contexts). This would explain in part why sensory-specific satiety occurs after just the taste of water in everyday conditions, as it is known that oropharyngeal stimulation can inhibit AVP secretion (Figaro \& Mack, 1997; Salata et al., 1987). If MDMA administration alters compartmental distribution of solutes (point (ii) above), it could mean that intracellular hypotonicity has a particular function in the regulation of thirst, independent of actual hydration status (body water). Such dysregulation could be the result of increased aquaporin receptor expression from MDMA ingestion (Bora et al., 2016). It seems unlikely that cellular hypotonicity is implicated in increased thirst as cellular dehydration/hyperosmolality has been reliably linked to thirst, but this option should not be excluded based solely on reverse logic.

Alternatively or additionally, ACh could be a regulator of MDMA-induced hyperhydration-type thirst. Unsurprisingly, relatively little research has been conducted, and none in the context of ACh-mediated MDMA-induced xerostomia or excess drinking. Nevertheless, MDMA does indeed interact centrally with mAChRs (specifically $M_{1}$ and $M_{2}$ receptors), increasing ACh release in the rat (Fischer et al., 2000; Nair \& Gudelsky, 2005). In theory, this should increase drinking so may provide a sensational-xerostomia, resulting in (excessive) drinking.

If ACh is being concentrated centrally, this may cause peripheral (i.e. salivary gland) depletion, also causing true-xerostomia. Whether local depletion of ACh occurs is undetermined though. Indeed, some have posited that the polydipsic effects of MDMA may be secondary to central signals (Brvar et al., 2004; Campbell \& Rosner, 2008; lovino \& Steardo, 1985), and research suggests in xerostomic patients dry mouth symptoms have little correlation with quantifiable saliva flow rate (Visvanathan \& Nix, 2010). This perhaps indicates central cholinergic effects (i.e. sensational-xerostomia) overwhelm any local effects (i.e. normal saliva flow rate), and as such why salivary stimulants (e.g. chewing gum) appear to offer only transient relief of symptoms in patients (Odusola, 1991; Stewart et al., 1998; Visvanathan \& Nix, 2010); as such this may apply to MDMA users if saliva flow rate is maintained.

Further, in native and cultured skeletal muscle and embryonic kidney cells, MDMA was found to be an nAChR agonist (Klingler et al., 2005). This model provides evidence for particular muscle-related symptoms that occur with MDMA ingestion, such as fasciculations, being related to dysregulation of the cholinergic system (Klingler et al., 2005), though may not offer much explanation towards hydration-related physiology.

As with alcohol, much MDMA-cholinergic research has focused on the (rat) brain, and as such, research in humans is warranted. Nonetheless, it is clear that alcohol and MDMA dysregulate the cholinergic system, dysregulate hydration physiology, and dysregulate thirst signalling regardless of actual hydration status (particularly in the hangover phase of alcohol). Additionally, the impact of such drugs on food/drink reward centres of the brain could also be investigated to understand whether neural pathways regulating water-induced sensory-specific satiety or palatability are affected. The fact that there are still several anomalies highlights the need for more research, and alternative pathways to be discovered. 


\section{Application and future research}

The above four-compartment model still fails to offer a complete understanding of thirst. Table 4 outlines key areas for future work. The historical context of different thirst appetites was provided, demonstrating that many of the ideas presented are unoriginal, but researchers may be working quite insularly and missing valuable data from other disciplines such as pharmacology and oral health sciences; such insularity should perhaps be reconciled going forward. Ideas to conceptualise the different components of thirst, and distinguish whether drinking behaviour is the sum of these components or related to a specific component are not particularly novel either (e.g. Block \& Fisher, 1975; Brunstrom, 2002; Inenago \& Ono, 2010); nevertheless, such ideas have never been actualised. Thus, in terms of future research, the ideas in this thesis need to be thoroughly critiqued and tested, and the four proposed subtypes of thirst and their interactions (if found to be valid) need to be refined in terms of their definition and operationalisation.

Pertaining to the thesis presented, key areas of work should consider:

- Accurately assessing cholinergic thirst in humans; current (predominantly rat) evidence suggests cholinergic stimulation causes saliva flow and drinking, and effects may be specific to the area of stimulation, but the role in perceptions of thirst and exactly how this related to drinking behaviours is unclear, particularly outside of a pharmacological setting

- Determine whether drug-induced xerogenic effects in humans cause changes in drinking, and therefore whether the model proposed herein is valid, both on a pharmaceutical level and in the application to the impulsive-thirst model

- Measuring choline status and cholinergic activity (e.g. circulating ACh) in hydration studies

- Investigating the effect of choline supplementation in athletes, older adults, hangover symptoms, and MDMA-users on drinking behaviours and thirst

- Measuring neural activity in relation to hyperhydration-induced excessive drinking

- Investigating thirst-related activity in the brain and mapping this to psychological constructs such as palatability and sensory-specific satiety; identifying whether these areas are different to true-thirst

- Investigating more broadly factors related to thirst and body water regulation, outside of the osmo-regulatory paradigm, and investigating the interactions between different thirst appetites (e.g. Table 4)

It would also be of merit to uncouple the effects of osmolality and AVP, particularly as there is some evidence that AVP may alter thirst or drinking behaviours (e.g. potentially during MDMA use), but also evidence that (in supraphysiological concentrations) it can be antidipsogenic (Fitzsimons, 1972; Pasqualini \& Codevilla, 1959). The osmolality-AVP relationship is often portrayed as simple and rather linear. However, ample examples exist whereby these two factors do not correlate (Table 5). This could mean there are moderating factors we are not currently accounting for, or that there are other factors altogether regulating thirst and drinking behaviours, such as cholinergic activity, or a multitude of other variables (Table 4). Considering the reduction in circulating AVP after just the taste of water, with concordant changes in thirst-related brain activity, AVP should perhaps be investigated in terms of its role in sensory-specific satiety.

Circadian rhythmicity may also play a role in cholinergic activity across the day (Watson et al., 2010), and interestingly this may interact with AVP, bearing some relation to our current understanding of thirst regulation (Hut et al., 2011). The cholinergic relation to AVP may provide clues into anticipatory thirst due to the role of AVP in cholinergically-mediated time 
1079 stamping in the suprachiasmatic nucleus (Hut et al., 2011). Beyond circadian rhythmicity,

1080 cholinergic variation across the day should additionally be investigated (along with interactions with AVP, angiotensin, etc). It does not appear unreasonable to have natural somewhat spontaneous small fluctuations in a neurotransmitter; thus fluctuations in daily ACh-induced 'thirst' (xerostomia) can be explained by analogy of other neurotransmitter effects, such as fluctuations in serotonergic activity in various regions across the day (Corthell et al., 2013; Hanson \& Hurley, 2014).

There is also merit in differentiating and validating different subtypes of thirst appetites; for example, scales for true-thirst, true-xerostomia, sensational-xerostomia/desire to drink, contextual/hedonic-thirst. Differentiating these to research participants would likely require (a validated way of) describing the unignorable sensation of true-thirst, and explaining the other types of thirst; speculatively for example, contextual thirst may simply be described as "how much do you want to drink for no obvious reason". To give one example of the applicability of this, in a study investigating the effect of hydration status on appetite, on average, participants consistently rated their thirst $\sim 30 \mathrm{~mm}$ higher (on a $100 \mathrm{~mm}$ visual analogue scale) when hypohydrated compared to euhydrated; however, their average thirst rating when euhydrated was still $\sim 60 \mathrm{~mm}$, despite all measured markers of hydration showing they were not hypohydrated (including copeptin, serum and urine osmolality, and urine specific gravity) (Carroll et al., 2019). Thus, participants were euhydrated but still reported quite high levels of thirst; differentiating the sensations they actually felt may have offered insight into their actual thirst status, including whether they just felt thirsty because they had abstained from fluid for a relatively long period (during the lab protocol), i.e. expectation effects.

Whilst understanding thirst may appear to be a mere academic and rather abstract exercise, there are multiple applications to developing a more holistic understanding. For example: helping to mitigate dehydration-induced medical complications in older adults; management of xerostomia from pharmacological interventions (thus improving quality of life); helping prevent endurance athletes and MDMA-users from dangerously excessive drinking; and helping reduce post-alcohol ingestion hangover symptoms. Further, interrelationships between hydration physiology and disease state can be established, for example the role of the cholinergic system in diabetic xerostomia (Wang et al., 2011), and the implications of this for metabolic health and quality of life.

More broadly, and in light of recent events, understanding factors affecting hydration physiology may have currently unknown applications. In this case, the novel coronavirus attaches to angiotensin-converting enzyme 2 receptors. If (for example) the cholinergic system is implicated in hydration physiology, it may provide clues as to protein binding/expression. The role of the cholinergic system in the novel coronavirus epidemic has been posited, specifically that of nicotine (an nAChR agonist) in potentially regulating angiotensin-converting enzyme 2 receptor expression and as such, smoking offering a rather counterintuitive possible protective role in disease severity (Farsalinos et al., 2020). Such interactions between the cholinergic system and angiotensin converting enzyme 2 may be altered by oestrogen (suggested below as a target for future research; Table 4) and the renin-angiotensin-aldosterone system (Farsalinos et al., 2020). Whether acute and/or chronic water intake could influence protein binding/expression is yet to be established. Thus, understanding the cholinergic system in terms of hydration physiology may have unexpected implications in the prevention, treatment, or recovery of diseases typically not considered when researching factors such as thirst that affect total body water regulation. 


\begin{tabular}{|c|c|c|}
\hline Theory & Explanation & Citation(s) \\
\hline $\begin{array}{l}\text { Uncoupling true- } \\
\text { thirst }\end{array}$ & $\begin{array}{l}\text { Uncouple the role of osmolality and AVP in thirst; understand the role of AVP in anticipatory thirst and sensory- } \\
\text { specific satiety }\end{array}$ & $\mathrm{N} / \mathrm{A}$ \\
\hline
\end{tabular}

thirst specific satiety

Explore whether fluctuations in cholinergic activity trigger drinking behaviours in every day life; understand the role of both mAChRs and nAChRs; investigate whether cholinergic activity in one area (e.g. the brain) can

Cholinergic thirst increase/decrease local (e.g. salivary gland) activity; whether choline supplementation can aid in mitigating

cholinergic thirst (e.g. pre-load before alcohol consumption or endurance activity, or prescribe supplementation for older adults)

Investigate whether there is a difference between true- and sensational-xerostomia, what drives these difference

Xerostomia

(e.g. neural activity, different cholinergic receptor binding?), and whether they are implicated in different drinking responses

Palatability and sensory-specific satiety pathways

Understand whether these food-appetite constructs apply to thirst appetites, including neuro-regulation (and whether this can be applied to our current neurological understanding of thirst regulation, or whether new pathways need to be sought)

Considering the high prevalence of pharmacological and illicit drugs that cause xerostomia and alter drinking behaviours acting on noradrenaline, serotonin, and dopamine, these are likely mechanisms to further understand Neurotransmitters thirst and hydration regulation. Other common drug pathways implicated in xerostomia should also be investigated and such as proton pump inhibitors and histamines. Rodent research has shown catecholamines to have a role in catecholamines hypertonicity-induced drinking responses. $\beta$-adrenergic drugs may stimulate drinking, perhaps mediated by the renin-angiotensin-aldosterone system; adrenergic stimulation of the lateral hypothalamus may block inhibit drinking in hypohydrated rats. $Y$-aminobutyric acid stimulates behaviour rewarded by water

Although our recent work showed no difference in fasted hypohydration versus euhydrated conditions, this

Fibroblast growth hormone may still be implicated in thirst (e.g. postprandial thirst, or drinking initiation); thus warrants further factor 21 human research

Prostaglandins Prostaglandins interact with AVP, and may therefore have a role in total body water regulation

Sex-hormones including across the menstrual

Water retention and altering of the osmo-setpoint of AVP are well-known across the menstrual cycle, thus it is likely an interaction of sex hormones (such as oestrogen, progesterone, prostaglandins, prolactin, etc) may impact body water balance and therefore thirst

cycle

Oxytocin is structurally similar to AVP, sharing similar roles, thus likely influences thirst and body water regulation.

Oxytocin The role of oxytocin in drinking behaviours may be mediated by endocannabinoids which should also be investigated

Amphetamines

Genetics, epigenetics, \& (early) life In animal models, amphetamines can depress drinking

Scully, 2003

Rolls et al., 1983; Saker et al., 2020

Block \& Fisher, 1975;

Fitzsimons, 1972, 1976;

Fitzsimons \& Setler, 1975;

Fregoneze et al., 2014;

Grossman, 1962, 1969;

Magrani et al., 2006; Scully,

2003; Zabik et al., 1993

Carroll et al., 2020

Anderson et al., 1975; Brooks et al., 1986; Yu et al., 1982

Horrobin et al., 1971;

Stachenfeld, 2010; White et al., 2011

Conrad et al., 1993; Rhodes et al., 1981 ; Van Tol et al., 1987; Verbalis et al., 1991 ; Verty et al., 2004

Mogenson, 1968

Recent theory has proposed these may influence osmoregulatory setpoints (or similar) so should be further investigated, including whether such influences could impact any other factor implicated in thirst regulation (as above)

experiences

Abbreviations: AVP, arginine vasopressin; mAChRs, muscarinic acetylcholine receptors ; nAChRs, nicotinic acetylcholine receptors

Rosinger, 2019 
Table 5. Areas in which the relationship between osmolality, arginine vasopressin, and thirst are unclear.

\begin{tabular}{|c|c|c|c|}
\hline & Osmolality & Arginine vasopressin & Thirst \\
\hline 3,4- methylenedioxymethamphetamine & $=/ \downarrow$ & $\uparrow$ & $\uparrow^{1}$ \\
\hline Diabetes insipidus & $\uparrow$ & $\downarrow$ & $\uparrow$ \\
\hline $\begin{array}{l}\text { Syndrome of inappropriate anti-diuretic } \\
\text { hormone secretion }{ }^{2}\end{array}$ & $=/ \downarrow$ & $\uparrow$ & $=$ \\
\hline Endurance exercise (extreme case) & $\downarrow$ & $\uparrow$ & $\uparrow$ \\
\hline Low-fluid drinkers & $\uparrow$ & $\uparrow$ & $\downarrow^{3}$ \\
\hline High-fluid drinkers & $\downarrow$ & $\downarrow$ & $\uparrow^{3}$ \\
\hline Adipsia 4 & $\uparrow$ & $\uparrow$ & $\downarrow$ \\
\hline
\end{tabular}

Symbols: ‘=' no change; ‘ ’ high; ' $\downarrow$ ' low; ‘’ or

It may be that different mechanisms regulate different types of thirst, for example, increased thirst with diabetes insipidus prevents hypohydration from excessive urination, thus water intake matches water losses (i.e. thirst per se is not dysregulated) (Fitzsimons, 1976). Such differentiation between symptomatic and pathological thirst may offer valuable mechanistic insights. See also Fitzsimons (1972) for a review of thirst regulatory issues regarding diabetes insipidus and syndrome of inappropriate antidiuretic hormone secretion, among other pathologies not described here. ${ }^{1}$ To note, sensations of xerostomia/thirst are variable (25-95\% prevalence; Baylen \& Rosenberg, 2006)

2Some variation depending on whether it is type A, B, or C (Gross, 2012); additionally, the act of drinking can quench thirst in this condition (Smith et al., 2004) (some have posited this is due to a shift in the osmo-set point, but it may be an example of sensory-specific satiety, which implicates other regulatory factors)

${ }^{3}$ This thirst response is assumed based on drinking behaviours

${ }^{4}$ To note, osmolality and arginine vasopressin concentrations may vary depending on the type $(A, B$, C, D) of adipsia; type A showed here as it differs from other models presented (except low-fluid drinkers) 
1129

1130

1131

1132

1133

1134

1135

1136

1137

1138

1139

1140

1141

1142

1143

1144

1145

1146

1147

1148

1149

1150

1151

\section{Conclusion}

Previous thirst research in various fields has focused on distinct types of thirst and how these may relate to drinking behaviour and therefore total body water regulation. This thesis proposes a unifying four-compartment model of thirst: true-thirst, contextual-thirst, pharmacological-thirst, and impulsive-thirst. These models collectively include classic osmoregulatory thirst and anticipatory thirst, but draw on knowledge from pharmacology to add the cholinergic system as a key initiator of impulsive, everyday thirst and drinking. Additionally, food-appetite constructs were introduced, namely explaining drinking volume and termination in terms of sensory-specific satiety and palatability. From these ideas, distinct sensations were proposed: true-thirst, true-xerostomia, and sensationalxerostomia-each of which warrant further investigation in terms of their mechanisms and validation in terms of their measurements.

The ideas proposed potentially address some gaps in our understanding of thirst, but there are still ample anomalies, demonstrating the incompleteness of the four-compartment model presented. Future research should broaden in scope, and several ideas were provided to help give some direction for further investigation. These theories, both independently and synergistically are largely theoretical and do not appear to have been considered in a unifying manner in a thirst context before. Thus, rigorous testing is needed to understand holistic thirst regulation and everyday drinking behaviours. The four-compartment model proposed proffers a conceptual theory; however understanding total body water regulation is highly complex and much is yet to be understood. 


\section{References}

Adolph, E. F., 1947. Water metabolism. Annual Review of Physiology, 9, 381-408, doi: 10.1146/annurev.ph.09.030147.002121.

Alles, G. A., 1934. The physiological significance of choline derivatives. Physiological Reviews, 14(2), 276, doi: 10.1152/physrev.1934.14.2.276.

Ali, A., Duizer, L., Foster, K., Grigor, J., \& Wei, W., 2011. Changes in sensory perception of sports drinks when consumed pre, during and post exercise. Physiology \& Behavior, 102(5), 437-43, doi: 10.1016/j.physbeh.2010.12.013.

Allison, D. B., 2014. Liquid calories, energy compensation, and weight: What we know and what we still need to learn. British Journal of Nutrition, 111(3), 384-6, doi:

10.1017/S0007114513003309.

Almond, C. S. D., Shin, A. Y., Fortescue, E. B., \& Mannix, R. C., 2005. Hyponatremia among runners in the Boston Marathon. New England Journal of Medicine, 352, 1550-6, doi: 10.1056/NEJMoa043901.

Anderson, R. J., Berl, T., McDonald, K. D., \& Schrier, R. W., 1975. Evidence for an in vivo antagonism between vasopressin and prostaglandin in the mammalian kidney. Journal of Clinical Investigation, 56(2), 420-6, doi: 10.1172/JCl108108.

Anguah, K. O., Lovejoy, J. C., Craig, B. A., Gehrke, M. M., Palmer, P. A., Eichelsdoerfer, P. E., \& McCrory, M. A., 2017. Can the Palatability of Healthy, Satiety-Promoting Foods Increase with Repeated Exposure during Weight Loss? Foods, 6(2), doi: 10.3390/foods6020016.

Appleton, K. M., 2005. Changes in the perceived pleasantness of fluids before and after fluid loss through exercise: A demonstration of the association between perceived pleasantness and physiological usefulness in everyday life. Physiology \& Behavior, 83(5), 813-9, doi: 10.1016/j.physbeh.2004.10.001.

Armstrong, L. E., \& Kavouras, S. A., 2019. Thirst and drinking paradigms: Evolution from single factor effects to brainwide dynamic networks. Nutrients, 11(12), 2864, doi: $10.3390 /$ nu11122864.

Baggott, M. J., Garrison, K. J., Coyle, J. R., Galloway, G. P., Barnes, A. J., Huestis, M. A., \& Mendelson, J. E., 2016. MDMA impairs response to water intake in healthy volunteers. Advances in Pharmacological Sciences, doi: 10.1155/2016/2175896.

Bargh, J. A., 1994. "The four horsemen of automaticity: Awareness, intention, efficiency, and control in social cognition", in Wyer Jr., R. S., \& Srull, T. K. (Eds.). Handbook of social cognition: Basic processes; Applications, Lawrence Erlbaum Associates, Inc, 1-40.

Baylen, C. A., \& Rosenberg, H., 2006. A review of the acute subjective effects of MDMA/ecstasy. Addiction, 101(7), 933-47, doi: 10.1111/j.1360-0443.2006.01423.x.

Beyer, C., Cappetta, K., Johnson, J. A., \& Bloch, M. H., 2017. Meta-analysis: Risk of hyperhidrosis with second-generation antidepressants. Depression \& Anxiety, 34(12), 113446, doi: 10.1002/da.22680.

Bichet, D. G., 2018. Vasopressin and the regulation of thirst. Annals of Nutrition and Metabolism, 72(Suppl 2), 3-7, doi: 10.1159/000488233. 
Blass, E. M. \& Chapman, H. W., 1971. An evaluation of the contribution of cholinergic mechanism to thirst. Physiology \& Behavior, 7(5), 649-86, doi: 10.1016/00319384(71)90131-4.

Block, M. L., \& Fisher, A. E., 1975. Cholinergic and dopaminergic blocking agents modulate water intake elicited by deprivation, hypovolemia, hypertonicity and Isoproterenol.

Pharmacology Biochemistry and Behavior, 3(2), 251-62, doi: 10.1016/0091-3057(75)901550 .

Bora, F., Yilmaz, F., \& Bora, T., 2016. Ecstasy (MDMA) and its effects on kidneys and their treatment: A review. Iranian Journal of Basic Medical Sciences, 19(11), 1151-8.

Boyd, L. D., Dwyer, J. T., \& Papas, A., 1997. Nutritional implication of xerostomia and rampant caries caused by serotonin reuptake inhibitors: A case study. Nutrition Reviews, 55(10), 362-8, doi: 10.1111/j.1753-4887.1997.tb01562.x.

Brooks, D. P., Crofton, J. T., \& Share, L., 1986. The role of brain prostaglandins in osmoticinduced vasopressin secretion in the rat. Proceedings of the Physiological Society, 12-14 September 1985, Cambridge Meeting: Communications Part II, 371(Suppl), 89-148 [Abstract only].

Brustrom, J. M., 2002. Effects of mouth dryness on drinking behavior and beverage acceptability. Physiology \& Behavior, 76, 423-9.

Brunstrom, J. M., MacRae, A. W., \& Roberts, B., 1997. Mouth-state dependent changes in the judged pleasantness of water at different temperatures. Physiology \& Behavior, 61(5), 667-9, doi: 10.1016/s0031-9384(96)00517-3.

Brunstrom, J. M., Tribbeck, P. M., \& MacRae, A. W., 2000. The role of mouth state in the termination of drinking behavior in humans. Physiology \& Behavior, 68(4), 579-83, doi: 10.1016/s0031-9384(99)00210-3.

Brvar, M., Kozelj, G., Osredkar, J., Mozina, M., Gricar, M., \& Bunc, M., 2004. Polydipsia as another mechanism of hyponatremia after 'ecstasy' (3,4 methyldioxymethamphetamine) ingestion. European Journal of Emergency Medicine, 11(5), 302-304. doi:10.1097/00063110-200410000-00014.

Burgio, K. L., Engel, B. T., \& Locher, J. L., 1991. Normative patterns of diurnal urination across 6 age decades. Journal of Urology, 145(4), 728-31, doi: 10.1016/S00225347(17)38436-7.Campbell, G. A., \& Rosner, M. H., 2008. The agony of ecstasy: MDMA (3,4-methylenedioxymethamphetamine) and the kidney. Clinical Journal of American Society of Nephrology, 3(6), 1852-60, doi: 10.2215/CJN.02080508.

Cannon, W. B., 1918. Croonian Lecture-The physiological basis of thirst. Proceedings of the Royal Society B (London), 90, 283-301, doi: 10.1098/rspb.1918.0017.

Carroll, H. A., Chen, Y-C., Templeman, I. S., James, L. J., Betts, J. A., \& Trim, W. V., 2020. The effect of hydration status on plasma FGF21 concentrations in humans: A subanalysis of a randomised crossover trial. PLOS ONE, in press.

Carroll, H. A., \& James, L. J., 2019. Hydration, arginine vasopressin, and glucoregulatory health in humans: A critical perspective. Nutrients, 11(6), doi: 10.3390/nu11061201.

Carroll, H. A., Templeman, I., Chen, Y-C., Edinburgh, R., Burch, E. K., Jewitt, J. T., Povey, G., Robinson, T. D., Dolley, W. L., Buckley, C., Rogers, P. J., Gallo, W., Melander, O., 
Thompson, D., James, L. J., Johnson, L., \& Betts, J. A., 2019. Hydration status affects thirst and salt preference but not energy intake or postprandial ghrelin in healthy adults: $A$ randomised crossover trial. Physiology \& Behavior, 212, 112725, doi: 10.1016/j.physbeh.2019.112725.

Chapman, H. W., \& Epstein, 1970. Prandial drinking induced by atropine. Physiology \& Behavior, 5(5), 549-54, doi: 10.1016/0031-9384(70)90079-X.

Conlay, L. A., Sabounjian, L. A., \& Wurtman, R. J., 1992. Exercise and neuromodulators: Choline and acetylcholine in marathon runners. International Journal of Sports Medicine, 13, S141-2.

Conrad, K. P., Gellai, M., North, W. G., \& Valtin, H., 1993. Influence of oxytocin on renal hemodynamics and sodium excretion. Annals of the New York Academy of Sciences, 689, 346-62, doi: 10.1111/j.1749-6632.1993.tb55559.x.

Cooke, L., \& Fildes, 2011. The impact of flavour exposure in utero and during milk feeding on food acceptance at weaning and beyond. Appetite, 57(3), 808-11, doi: 10.1016/j.appet.2011.05.317.

Corbin, K. D., \& Zeisel, S. H., 2012. Choline metabolism provides novel insights into nonalcoholic fatty liver disease and its progression. Current Opinion in Gastroenterology, 28(2), 159-65, doi: 10.1097/MOG.0b013e32834e7b4b.

Corthell, J. T., Stathopoulos, A. M., Watson, C. C., Bertram, R., \& Trombley, P. Q., 2013. Olfactory bulb monoamine concentrations vary with time of day. Neuroscience, 247, 234-41, doi: 10.1016/j.neuroscience.2013.05.040.

Cummings, D. E., 2006. Ghrelin and the short- and long-term regulation of appetite and body weight. Physiology \& Behavior, 89(1), 71-84.

Davies, I., O’Neill, P. A., McLean, K. A., Catania, J., \& Bennett, D., 1995. Age-associated alterations in thirst and arginine vasopressin in response to a water or sodium load. Age \& Ageing, 24(2), 151-9, doi: 10.1093/ageing/24.2.151.

Dawson, L., Tobin, A., Smith, P., \& Gordon, T., 2005. Antimuscarinic antibodies in Sjögren's syndrome: Where are we, and where are we going? Arthritis and Rheumatism, 52(10), doi: 10.1002/art.21347.

Daly, C., 2016. Oral and dental effects of antidepressants. Australian Prescriber, 39(3), 84, doi: 10.18773/austprescr.2016.035.

Enhörning, S., Brunkwall, L., Tasevska, I., Ericson, U., Tholin, J. P., Persson, M., Lemetais, G., Vanhaecke, T., Dolci, A., Perrier, E. T., \& Melander, O., 2019b. Water supplementation reduces copeptin and plasma glucose in adults with high copeptin: The $\mathrm{H} 2 \mathrm{O}$ metabolism pilot study. Journal of Clinical Endocrinology \& Metabolism, 104(6), 1917-25, doi: 10.1210/jc.2018-02195.

Enhörning, S., Tasevska, I., Roussel, R., Bouby, N., Persson, M., Burri, P., Bankir, L., \& Melander, O., 2019a. Effects of hydration on plasma copeptin, glycemia and glucoregulatory hormones: A water intervention in humans. European Journal of Nutrition, 58, 315-24, doi: 10.1007/s00394-017-1595-8.

Farsalinos, K., Niaura, R., Le Houezec, J. Barbouni, A., Tsatsakis, A., Kouretas, D., Vantarakis, A., \& Poulas, K., 2020. Editorial: Nicotine and SARS-CoV-2: COVID-19 may be 
a disease of the nicotinic cholinergic system. Toxicology Reports, 7, 658-663, doi: 10.1016/j.toxrep.2020.04.012.

Feduccia, A. A., Chatterjee, S., \& Bartlett, S. E., 2012. Neuronal nicotinic acetylcholine receptors: Neuroplastic changes underlying alcohol and nicotine addictions. Frontiers in Molecular Neuroscience, 5(83), doi: 10.3389/fnmol.2012.00083.

Figaro, M. K., \& Mack, G. W., 1997. Regulation of fluid intake in dehydrated humans: Role of oropharyngeal stimulation. American Journal of Physiology, 272(6 pt.2), R1740-6, doi: 10.1152/ajpregu.1997.272.6.R1740.

Fischer, H. S., Zernig, G., Schatz, D. S., Humpel, C., \& Saria, A., 2000. MDMA ('ecstasy') enhances basal acetylchoine release in brain slices of the rat striatum. European Journal of Neuroscience, 12(4), 1385-90, doi: 10.1046/j.1460-9568.2000.00004.x.

Fitzsimons, J. T., 1972. Thirst. Physiological Reviews, 52(2), 468-561.

Fitzsimons, J. T., 1976. The physiological basis of thirst. Kidney International, 10, 3-11.

Fitzsimons, J. T., \& Setler, P. E., 1975. The relative importance of central nervous catecholaminergic and cholinergic mechanisms in drinking in response to angiotensin and other thirst stimuli. Journal of Physiology, 250(3), 613-31, doi:

10.1113/jphysiol.1975.sp011073.

Fraser, F. R., 1938. The clinical aspects of the transmission of the effects of nervous impulses by acetylcholine. British Medical Journal, 1(4040), 1249-54, doi: 10.1136/bmj.1.4040.1249.

Fregoneze, J. B., Ferreira, H. S., \& Luz, C. P. N., 2014. "Brain serotonergic receptors and control of fluid intake and cardiovascular function in rats", in De Luca, L. A., Menani, J. V., Johnson, A.

K. (Eds.). Neurobiology of body fluid homeostasis: Transduction and Integration, CRC Press/Taylor Francis, Florida.

Gaddum, J. H., 1935. Choline and allied substances. Annual Review of Biochemistry, 4, 311-30, doi: 10.1146/annurev.bi.04.070135.001523.

Gholami, N., Sabzvari, B. H., Razzaghi, A., \& Salah, S., 2017. Effect of stress, anxiety and depression on unstimulated salivary flow rate and xerostomia. Journal of Dental Research, Dental Clinics, Dental Prospects, 11(4), 247-52, doi: 10.15171/joddd.2017.043.

Gibson, G. E., \& Peterson, C., 1981. Aging decreases oxidative metabolism and the release and synthesis of acetylcholine. Journal of Neurochemistry, 37(4), doi: 10.1111/j.1471-

4159.1981.tb04484.x.

Gizowski, C., \& Bourque, C. W., 2018. The neural basis of homeostatic and anticipatory thirst. Nature Reviews Nephrology, 14, 11-25, doi: 10.1038/nrneph.2017.149.

Gizowski, C., Zaelzer, C., \& Bourque, C. W., 2016. Clock-driven vasopressin neurotransmission mediates anticipatory thirst prior to sleep. Nature, 537, 685-8, doi: 10.1038/nature19756.

Gonzalez, A., Recio, S. A., Sanchez, J., Gil, M., \& de Brugada, I., 2018. Effect of exposure to similar flavours in sensory specific satiety: Implications for eating behaviour. Appetite, 127, 289-295

Gross, P., 2012. Clincal management of SIADH. Therapeutic Advances in Endocrinology and Metabolism, 3(2), 61-73, doi: 10.1177/2042018812437561. 
Grossman, S. P., 1960. Eating and drinking elicited by direct adrenregic or cholinergic stimulation of hypothalamus. Science, 132, 301-302.

Grossman, S. P., 1962. Effects of adrenergic and cholinergic blocking agents on hypothalamic mechanisms. American Journal of Physiology, 202(6), 1230-6, doi: 10.1152/ajplegacy.1962.202.6.1230.

Grossman, S. P., 1969. A neuropharmacological analysis of hypothalamic and extrahypothalamic mechanisms concerned with the regulation of food and water intake. Annals of the New York Academic of Sciences, 157(2), 902-12, doi: 10.1111/j.17496632.1969.tb12927.x.

Grotenhermen, F., \& Müller-Vahl, K., 2012. The therapeutic potential of cannabis and cannabinoids. Deutches Arzteblatt International, 109(29-30), 495-501, doi: 10.3238/arztebl.2012.0495.

Government Officer for Science, 2007. Reducing obesity: Obesity system map [online]. https://www.gov.uk/government/publications/reducing-obesity-obesity-system-map (accessed 17 June 2020).

Guyenet, S. J., \& Schwartz, M. W., 2012. Clinical review: Regulation of food intake, energy balance, and body fat mass: implications for the pathogenesis and treatment of obesity. Journal of Clinical Endocrinology and Metabolism, 97(3), 745-55.

Hanson, J. L., \& Hurley, L. M., 2014. Context-dependent fluctuation of serotonin in the auditory midbrain: The influence of sex, reproductive state and experience. Journal of Experimental Biology, 217, 526-35, doi: 10.1242/jeb.087627.

Henderson, L. M., Guildford, M. J., \& Tapper, A. R., 2013. Neuronal nicotinic acetylcholine receptors: Common molecular substrates of nicotine and alcohol dependence. Frontiers in Psychiatry, 4(29), doi: 10.3389/fpsyt.2013.00029.

Henry, J. A., Fallon, J. K., Kicman A. T., Hutt, A. J., Cowan, D. A.,\& Forsling, M., 1998. Lowdose MDMA ("ecstasy") induces vasopressin secretion. Lancet, 351, doi: 10.1016/S01406736(05)78744-4.

Herrera Moro Chao, D., Argmann, C., Van Eijk, M., Boot, R.G., Ottenhoff, R., Van Roomen, C., Foppen, E., Siljee, J. E., Unmehopa, U. A., Kalsbeek, A., \& Aerts, J. M., 2016. Impact of obesity on taste receptor expression in extra-oral tissues: emphasis on hypothalamus and brainstem. Scientific Reports, 6, doi: 10.1038/srep29094.

Hetherington, M., Rolls, B. J. \& Burley, V. J., 1989. The time course of sensory-specific satiety. Appetite, 12(1) 57-68.

Hobson, R. M., \& Maughan, R. J., 2010. Hydration status and the diuretic action of a small dose of alcohol. Alcohol and Alcoholism, 45(4), 366-73, doi: 10.1093/alcalc/agq029.

Honda, E., Ono, K., Toyono, T., Kawano, H., Masuko, S., \& Inenaga, K., 2003. Activation of muscarinic receptors in rat subfornical organ neurones. Journal of Neuroendocrinology, 15(8), 770-7, doi: 10.1046/j.1365-2826.2003.01057.x.

Hopcraft, M. S., \& Tan, C., 2010. Xerostomia: An update for clinicians. Australian Dental Journal, 55(3), 238-44, doi: 10.1111/j.1834-7819.2010.01229.x. 
Horrobin, D. F., Lloyd, I. J., Lipton, A., Burstyn, P. G., Durkin, N., \& Muiruri, K. L., 1971. Actions of prolactin on human renal function, Lancet, 298(7720), 352-4, doi: 10.1016/S01406736(71)90065-1.

Howland, J., Rohsenow, D. J., Greece, J., Almeida, A., Minsky, S. J., Allensworth-Davies, D., Arnedt, J. T., \& Hermos, J., 2013. The incidence and severity of hangover the morning after moderate alcohol intoxication. Addiction, 103(5), doi: 10.1111/j.13600443.2008.02181.x.

Hut, R. A., \& Van der Zee, E. A., 2011. The cholinergic system, circadian rhythmicity, and time memory. Behavioural Brain Research, 221(2), 466-80, doi: 10.1016/j.bbr.2010.11.039.

Inenaga, K., \& Ono, K., 2010. Oral dryness and thirst-The central effect of acetylcholine on drinking behavior. Journal of Oral Biosciences, 52(4), 344-51, doi: 10.1016/S13490079(10)80015-5.7

Inenaga, K., Ono, K., Hitomi, S., Kuroki, A., \& Izumi, U., 2017. Thirst sensation and oral dryness following alcohol intake. Japanese Dental Science Review, 53(3), 78-85, doi: 10.1016/j.jdsr.2016.12.001.

lovino, M., \& Steardo, L., 1985. Effect of substances influencing brain serotonergic transmission on plasma vasopressin levels in the rat. European Journal of Pharmacology, 113, 99-103, doi: 10.1016/0014-2999(85)90347-4.

Jewell, P. A., 1953. The occurrence of vesiculated neurones in the hypothalamus of the dog. Journal of Physiology, 121, 167-81, doi: 10.1113/jphysiol.1953.sp004938.

Jewell, P. A., \& Verney, E. B., 1957. An experimental attempt to determine the site of neurohypophysial osmoreceptors in the dog. Philosophical Transactions of the Royal Society, B Biological Sciences240(672), doi: 10.1098/rstb.1957.0002.

Johnson, A. K., 2007. The sensory psychobiology of thirst and salt appetite. Medicine and Science in Sports and Exercise, 39(8), 1388-400.

Kavouras, S. A., 2019. Hydration, dehydration, underhydration, optimal hydration: Are we barking up the wrong tree? European Journal of Nutrition, 58, 471-3, doi: 10.1007/s00394018-01889-z.

Kanter, M. M., \& Williams, M. H., 1995. Antioxidants, carnitine, and choline as putative ergogenic aids. International Journal of Sports Nutrition, 5, S120-31.

Kenney, W. L., \& Chiu, P., 2001. Influence of age on thirst and fluid intake. Medicine \& Science in Sports \& Exercise, 33(9), 1524-32.

Klingler, W., Heffron, J. J., Jurkatt-Rott, K., O'Sullivan, G., Alt, A., Schlesinger, F., Bufler, J., \& Lehmann-Horn, F., 2005. 3,4-Methylenedioxymethamphetamine (Ecstasy) activates skeletal muscle nicotinic acetylcholine receptors. Journal of Pharmacology \& Experimental Therapeutics, 314(3), 1267-73, doi: 10.1124/jpet.105.086629.

Kruger, J., Glassman, J., Knippen, K. L., Glassman, T., Kruger, D. J., 2018. The drunchies hangover: Heavy episodic drinking and dietary choices while drinking and on the following day. Californian Journal of Health Promotion, 16, 79-90.

Kunkle, E. C., 1959. Acetylcholine in the Mechanism of Headaches of Migraine Type. Archives of Neurology And Psychiatry, 81(2), 135-41, doi:10.1001/archneurpsyc.1959.0234014000100. 
Larsson, A., Edström, L., Svensson, L., Söderpalm, B., \& Engel, J. A., 2005. Voluntary ethanol intake increases extracellilar Acetylcholine levels in the ventral tegmental area in the rat. Alcohol Alcohol, 40(5), 349-58, doi: 10.1093/alcalc/agh180.

Lemon, J., 1993. Alcoholic hangover and performance: a review. Drug and Alcohol Review, 12(3), 299-314, doi:10.1080/09595239300185361.

Levitt, R. A., 1969. Biochemical blockade of cholinergic thirst. Psychonomic Science, 15, 274-6, doi: 10.3758/BF03337420.

Levitt, R. A, \& Fisher, A. E., 1966. Anticholinergic blockade of centrally induced thirst. Science, 154, 520-2, doi: 10.1126/science.154.3748.520.

Levitt, R. A., \& Fisger, A. E., 1967. Failure of central anticholinergic brain stimulation to block natural thirst. Physiology \& Behavior, 2(4), 425-8, doi: 10.1016/0031-9384(67)90063-7.

Li, J., Ha, Y-M., Kü, N-Y., Choi, S-Y., Lee, S. J., Oh, S. B., Kim, J-S., Hee, J-H., Lee, E. B., Song, Y. W., \& Park, K., 2004. Inhibitory effects of autoantibodies on the muscarinic receptors in Sjögren's syndrome. Laboratory Investigation; A Journal of Technical Methods and Pathology, 84(11), 1430-8, doi: 10.1038/labinvest.3700173.

Liljestrand, G., \& Zotterman, Y., 1954. The water taste in mammals. Acta Physiologica Scandinavica, 32(4), 291-303, doi: 10.1111/j.1748-1716.1954.tb01177.x.

Magrani, J., de Castro e Silva, E., Athanazio, R., Improta, L., Fregoneze, J. B., 2006. Involvement of central $\mathrm{H}_{1}$ and $\mathrm{H}_{2}$ receptors in water intake induced by hyperosmolalrity, hypovolemia and central cholinergic stimulation. Physiology \& Behavior, 89(2), 241-9, doi: 10.1016/j.physbeh.2006.06.004.

Mandelblat-Cerf, Y., Kim, A., Burgess, C. R., Subramanian, S., Tannous, B. A., Lowell, B. B., \& Andermann, M. L., 2017. Bidirectional anticipation of future osmotic challenges by vasopressin neurons. Neuron, 93, 57-65, doi: 10.1016/j.neuron.2016.11.021.

Mangiapane, M. L., \& Simpson, J. B., 1983. Drinking and pressor responses after acetylcholine injection into subfornical organ. American Journal of Physiology-Regulatory, Integrative and Comparative Physiology, 244(4), R508-13, doi:

10.1152/ajpregu.1983.244.4.R508.

Mangot, A. G., 2013. Bad trip dur to anticholinergic effect of cannabit. General Hospital Psychiatry, 35(6), 682.e5-682.e6, doi: 10.1016/j.genhosppsych.2013.06.010.

Mark, G. P., Rada, P., Pothos, E., \& Hoebel, B. G., 1992. Effects of feeding and drinking on acetylcholine release in the nucleus accumbens, striatum, and hippocampus of freely behaving rats. Journal of Neurochemistry, 58(6), 2269-74, doi: 10.1111/j.14714159.1992.tb10973.x.

Maughan, R. J., Watson, P., Cordery, P. A. A., Walsh, N. P., Oliver, S. J., Dolci, A., Rodriguez-Sanchez, N., \& Galloway, S. D. R., 2016. A randomized trial to assess the potential of different beverages to affect hydration status: Development of a beverage hydration index. American Journal of Clinical Nutrition, 103(3), 717-23, doi: 10.3945/ajcn.115.114769.

Menani, J., Saad, W., Camargo, L., Antunesrodrigues, J., Covian, M., \& Saad, W.., 1984. Effect of cholinergic and adrenergic stimulation of the subfornical organ on water intake. Pharmacology Biochemistry \& Behavior, 20(2), 301-6, doi: 10.1016/0091-3057(84)90258-2. 
Methven, L., Allen, V. J., Withers, C. A., \& Gosney, M. A., 2012. Ageing and taste. Proceedings of the Nutrition Society, 71(4), 556-65, doi: 10.1017/S0029665112000742.

Meyer, J., \& Necheles, H., 1940. Studies in old age: IV. The clinical significance of salivary, gastric and pancreatic secretion in the aged. Journal of the American Medical Association, 115(24), 2050-5, doi: 10.1001/jama.1940.02810500018005.

Miller, M., 2015. Nocturnal polyuria in older people: Pathophysiology and clinical implications. Journal of the American Geriatrics Society, 48(10), 1321-9, doi: 10.1111/j.15325415.2000.tb02608.x.

Mistlberger, R. E., 2011. Neurobiology of food anticipatory circadian rhythms. Physiology \& Behavior, 104(4), 535-45, doi: 10.1016/j.physbeh.2011.04.015.

Mogenson, G. J., 1968. Effects of amphetamine on self-stimulation and induced drinking. Physiology \& Behavior, 3, 133-6, doi: 10.1016/0031-9384(68)90043-7.

Montgomery, M. F., 1931. The role of the salivary glands in the thirst mechanism. American Journal of Physiology, 96, 221-7, doi: 10.1152/ajplegacy.1931.96.1.221.

Morris, C. J., Yang, J. N., Garcia, J. I., Myers, S., Bozzi, I., Wang, W., Buxton, O. M., Shea, S. A., \& Scheer, F. A. J. L., 2015. Endogenous circadian system and circadian misalignment impact glucose tolerance via separate mechanisms in humans. Proceedings of the National Academy of Sciences, 112(17), E2225-34, doi: 10.1073/pnas.1418955112.

Muir, J. L., 1997. Acetylcholine, aging, and Alzheimer's disease. Pharmacology Biochemistry \& Behavior, 56(4), 678-96, doi: 10.1016/S0091-3057(96)00431-5.

Nair, S. G., \& Gudelsky, G. A., 2005. 3,4-Methylenedioxymethamphetamine (MDMA) enhances the release of acetylcholine by $5-\mathrm{HT} 4$ and D1 receptor mechanisms in the rat prefontal cortex. Synapse, 58(4), 229-35, doi: 10.1002/syn.20202.

Närhi, T. O., Meurman, J. H., \& Ainamo, A., 1999. Xerostomia and hyposalivation. Drugs \& Aging, 15(2), 103-116, doi: 10.2165/00002512-199915020-00004.

Odusola, F., 1991. Chewing gum as aid in treatment of hyposalivation. New York State Dental Journal, 57(4), 28-31.

O’Neill, P. A., \& McLean, K. A., 1992. Water homeostasis and ageing. Medical Laboratory Sciences, 49(4), 291-8.

Ono, M., Takamura, E., Shinozaki, K., Tsumura, T., Hamano, T., Yagi, Y., \& Tsubota, K., 2004. Therapeutic effect of cevimeline on dry eye in patients with Sjögren's syndrome: A randomized, double-blind clinical study. American Journal of Ophthalmology, 138, 6-17, doi: 10.1016/j.ajo.2004.02.010.

Ono, K., Toyono, T., \& Inenaga, K., 2008. Nicotonic receptor subtypes in rat subfornical organ neurons and glial cells. Neuroscience, 154(3), 994-1001, doi:

10.1016/j.neuroscience.2008.04.028.

Parker, T. H., Roberts, R. K., Henderson, G. I., Hoyumpa Jr., A. M., Schmidt, D. E., Schenker, S., 1978. The effects of ethanol on cerebral regional acetylcholine concentration and utilization. Proceedings of the Society for Experimental Biology and Medicine, 159 (2), 270-5, doi: 10.3181/00379727-159-40330. 
Pasqualini, R. Q., \& Codevilla, A., 1959. Thirst-suppressing ('antidipsetic') effect of pitressin in diabetes insipidus. European Journal of Endocrinology, 30, 37-41, doi: 10.1530/acta.0.0300037.

Penning, R., van Nuland, M., Fliervoet, L. A. L., Olivier, B., \& Verster, J. C., 2010. The pathology of alcohol hangover. Current Drug Abuse Reviews, 3(2), 68-75, doi: $10.2174 / 1874473711003020068$.

Penry, J. T., \& Manore, M. M., 2008. Choline: An important micronutrient for maximal endurance-exercise performance? International Journal of Sports Nutrition and Exercise Metabolism, 18, 191-203.

Perrier, E., Vergne, S., Klein, A., Poupin, M., Rondeau, P., Le Bellego, L., Armstrong, L. E., Lang, F., Stookey, J., \& Tack, I., 2013. Hydration biomarkers in free-living adults with different levels of fluid consumption. British Journal of Nutrition, 109(9), 1678-87, doi: $10.1017 /$ S0007114512003601.

Phillips, P. A., Johnston, C. I., \& Gray, L., 1993. Disturbed electrolyte homeostasis following dehydration in elderly people. Age \& Ageing, 22(Suppl 1), S26-33, doi: 10.1093/ageing/22.suppl_1.S26.

Phillips, P. A., Rolls, B. J., Ledingham, J. G. G., \& Morton, M. J., 1984. Body fluid changes, thirst and drinking in man during free access to water. Physiology \& Behavior, 33(3), 357-63, doi: 10.1016/0031-9384(84)90154-9.

Pickford, M., 1939. The inhibitory effect of acetylcholine on water diuresis in the dog, and its pituitary transmission. Journal of Physiology, 95, 226-238, doi:

10.1113/jphysiol.1939.sp003721.

Quarterman, D., \& Miller, N. E., 1966. Sensory feedback in time response of drinking elicited by carbachol in preoptic area of rat. Journal of Comparative \& Physiological Psychology, 62(3), 350-3, doi: 10.1037/h0023932.

Rada, P. V., Mark, G. P., Yeomans, J. J., \& Hoebel, B. G., 2000. Acetylcholine release in ventral tegmental area by hypothalamic self-stimulation, eating, and drinking. Pharmacology Biochemistry \& Behavior, 65(3), 375-9, doi: 10.1016/S0091-3057(99)00218-X.

Ramsay, D. J., 1989. The importance of thirst in maintenance of fluid balance. Baillière's Clinical Endocrinology and Metabolism, 3(2), 371-91, doi: 10.1016/s0950-351x(89)80008-4.

Rhodes, C. H., Morrell, J. I., \& Pfaff, D. W., 1981. Changes in oxytocin content in the magnocellular neurons of the rat hypothalamus following water deprivation or estrogen treatment. Quantitative immunohyistological studies. Cell \& Tissue Research, 216, 47-55, doi: 10.1007/BF00234544.

Robertson, G. L., 1984. Abnormalities of thirst regulation. Kidney International, 25(2), 460-9.

Rogers, P. J., \& Hardman, C. A., 2015. Food reward. What it is and how to measure it. Appetite, 90, 1-15, doi: 10.1016/j.appet.2015.02.032.

Rolls, B. J., 1986. Sensory-specific satiety. Nutrition Reviews, 44(3), 93-101.

Rolls, B. J., \& Phillips, P. A., 1990. Aging disturbances of thirst and fluid balance. Nutrition Reviews, 48(3), 137-44, doi: 10.1111/j.1753-4887.1990.tb02915.x.

Rolls, B. J., \& Rolls, E. T., 1982. "Thirst" in Grey, J., Gelder, M., Gregory, R., Hinde, R., \& Lonquet-Higgins, C. (Eds.). Problems in the Behavioural Sciences, CUP Archive, 1-191. 
Rolls, B. J., Rolls, E., Rowe, E., \& Sweeney, K., 1981. Sensory specific satiety in man. Physiology \& Behavior, 27(1), 137-42.

Rolls, E. T., Rolls, B. J., \& Rowe, E. A., 1983. Sensory-specific and motivation-specific satiety for the sight and taste of food and water in man. Physiology \& Behavior, 185-92.

Rolls, E. T., \& Rolls, J. H., 1997. Olfactory sensory-specific satiety in humans. Physiology \& Behavior, 61(3), 461-73.

Rolls, E. T., Scott, T. R., Sienkiewicz, Z. J., \& Yaxley, S., 1988. The responsiveness of neurones in the frontal opercular gustatory cortex of the macaque monkey is independent of hunger. Journal of Physiology, 397(1), 1-12

Rolls, B. J., Van Duijvenvoorde, P. M. \& Rolls, E. T., 1984. Pleasantness changes and food intake in a varied four-course meal. Appetite, 5(4), 337-48.

Rolls, B. J., R. J. Wood, E. T. Rolls, H. Lind, R. Lind, \& J. Ledingham, 1980. Thirst following water deprivation in humans. American Journal of Physiology, 239(5), R476-82, doi: 10.1152/ajpregu.1980.239.5.R476.

Rosenson, J., Smollin, C., Sporer, K. A., Blanc, P., \& Olson, K. R., 2007. Patterns of ecstasy-associated hyponatraemia in California. Annals of Emergency Medicine, 49(2), 16471, doi: 10.1016/j.annemergmed.2006.09.018.

Rosinger, A., 2019. Biobehavioural variation in human water needs: How adaptations, early life environments, and the life course affect body water homeostasis. American Journal of Human Biology, 32, doi: 10.1002/ajhb.23338.

Saker, P., Carey, S., Grohmann, M., Farrell, M. J., Ryan, P. J., Egan, G. F., McKinley, M. J., \& Denton, D. A., 2020. Regional brain responses associated with using imagination to evoke and satiate thirst. Proceedings of the National Academy of Sciences, 117(24), 13750-6, doi: 10.1073/pnas.2002825117.

Salata, R. A., Verbalis, J. G., \& Robinson, A. G., 1987. Cold water stimulation of oropharyngeal receptors in man inhibits release of vasopressin. Journal of Clinical Endocrinology \& Metabolism, 65(3), 561-7, doi: 10.1210/jcem-65-3-561.

Schmidt, H., Moak, S. J., \& Van Meter, W. G., 1958. Atropine Depression of Food and Water Intake in the Rat. American Journal of Physiology-Legacy Content, 192(3), 543-5, doi:10.1152/ajplegacy.1958.192.3.543.

Scully, C., 2003. Drug effects on salivary glands: Dry mouth. Oral Diseases, 9(4), doi: 10.1034/j.1601-0825.2003.03967.x.

Sharif-Naeini, R., Ciura, S., Zhang, Z. \& Bourque, C. W., 2008. Contribution of TRPV channels to osmosensory transduction, thirst, and vasopressin release. Kidney International, 73(7), 811-5.

Siegel, P. S., \& Pilgrim, F. J., 1958. The effect of monotony on the acceptance of food. American Journal of Psychology, 71(4), 756-9.

Simmler, L. D., Hysek, C. M., \& Liechti, M. E., 2011. Sex differences in the effects of MDMA (ecstasy) on plasma copeptin in healthy subjects. Journal of Clinical Endocrinology \& Metabolism, 96, 2844-2850, doi: 10.1210/jc.2011-1143.

Simpson, J. B., \& Routtenberg, A., 1973. Subfornical organ: Site of drinking elicitation by angiotensin II. Science, 181(4105), 1172-5, doi: 10.1126/science.181.4105.1172. 
Simpson, J. B., \& Routtenberg, A., 1974. Subfornical organ : Acetylcholine application elicits drinking. Brain Research, 70, 157-64, doi: 10.1016/0006-8993(74)90576-9.

Smith, D., Moore, K., Tormey, W., Baylis, P. H., \& Thompson, C. J., 2004. Downward resetting of the osmotic threshold for thirst in patients with SIADH. American Journal of Physiology: Endocrinology \& Metabolism, 287(5), E1019-23, doi :

10.1152/ajpendo.00033.2004.

Sorensen, J. P., \& Harvey, J. A., 1971. Decreased brain acetylcholine after septal lesions in rats: Correlation with thirst. Physiology \& Behavior, 6(6), 723-725. doi:10.1016/00319384(71)90261-7.

Sorensen, L. B., Moller, P., Flint, A., Martens, M., \& Raben, A., 2003. Effect of sensory perception of foods on appetite and food intake: a review of studies on humans. International Journal of Obesity and Related Metabolic Disorders, 27(10), 1152-66

Sreebny, L. M., \& Schwartz, S. S., 1997. A reference guide to drugs and dry mouth -2 2nd edition. Gerodontology, 14, 33-47, doi: 10.1111/j.1741-2358.1997.00033.x.

Stachenfeld, N. S., 2010. Sex hormone effects on body fluid regulation. Exercise and Sport Sciences Reviews, 36(3), 152-9, doi: 10.1097/JES.0b013e31817be928.

Steggerda, F. R., 1941. Observations on the water intake in an adult man with dysfunctioning salivary glands. American Journal of Physiology, 132(2), 517-21, doi: 10.1152/ajplegacy.1941.132.2.517.

Stewart, C. M., Jones, A. C., Bates, R. E., Sandow, P., Pink, F., \& Stillwell, J., 1998. Comparison between saliva stimulants and saliva substitute in patients with xerostomia and hyposalivation. Special Care in Dentistry, 18(4), 142-8, doi: 10.1111/j.17544505.1998.tb01136.x.

Stout, N. R., Kenny, R. A., \& Baylis, P. H., 1999. A review of water balance in ageing in health and disease. Gerontology, 45, 61-6, doi: 10.1159/000022063.

Sumida, T., Tsuboi, H., lizuka, M., Asashima, H., \& Matsumoto, I., 2013. Anti-M3 muscarinic acetylcholine receptor antibodies in patients with Sjögren's syndrome. Modern Rheumatology, 23(5), 841-5. doi:10.3109/s10165-012-0788-5.

Sumida, T., Tsuboi, H., lizuka, M., Hirota, T., Asashima, H., \& Matsumoto, I., 2014. The role of M3 muscarinic acetylcholine receptor reactive T cells in Sjögren's sundrom: A critical review. Journal of Autoimmunity, 51, 44-50, doi: 10.1016/j.jaut.2013.12.012.

Taivainen, H., Laitinen, K., Tähtela, R, Kiianmaa, K., Välimäki, M. J., 1995. Role of plasma vasopressin in changes of water balance accompanying acute alcohol intoxication.

Alcoholism: Clinical and Experimental Research, 19(3), doi: 10.1111/j.15300277.1995.tb01579.x.

Thornton, S. N., 2010. Thirst and hydration: physiology and consequences of dysfunction. Physiology \& Behavior, 100(1), 15-21

Treloar, H. R., Piasecki, T. M., McCarthy, D. E., \& Baker, T. B., 2014. Relations among caffeine consumption, smoking, smoking urge, and subjective smoking reinforcement in daily life. Journal of Caffeine Research, 4(3), 93-9, doi: 10.1089/jcr.2014.0007. 
Van Tol, H. H., Voorhuis, D. T., \& Burbach, J. P., 1987 Oxytocin gene expression in discrete hypothalamic magnocellular cell groups is stimulated by prolonged salt loading.

Endocrinology, 120, 71-6, doi: 10.1210/endo-120-1-71.

Verbalis, J. G., Mangione, M. P., \& Stricker, E. M., 1991. Oxytocin produces natriuresis in rats at physiological plasma concentrations. Endocrinology, 128(3), 1317-22, doi:

10.1210/endo-128-3-1317.

Verney, E. B., 1947. The antidiuretic hormone and the factors which determine its release. Proceedings of the Royal Society of London. Series B, Biological Sciences. 135(878), 25106.

Verplanken, B., \& Roy, D., 2016. Empowering interventions to promote sustainable lifestyles: Testing the habit discontinuity hypothesis in a field experiment. Journal of Environmental Psychology, 45, 127-34, doi: 10.1016/j.jenvp.2015.11.008.

Verty, A. N. A., McFarlane, J. R., McGregor, I. S., \& Mallet, P. E. Evidence for an interaction between $\mathrm{CB}_{1}$ cannabinoid and oxytocin receptor in food and water intake.

Neuropharmacology, 47(4), 593-603, doi: 10.1016/j.neuropharm.2004.06.002.

Visvanathan, V., \& Nix, P., 2010. Managing the patient presenting with xerostomia: A review. International Journal of Clinical Practice, 64(3), 404-7, doi: 10.1111/j.17421241.2009.02132.x.

Wang, D., Yuan, Z., Inoue, N., Cho, G., Shono, M., \& Ishikawa, Y., 2011. Abnormal subcellular localization of AQP5 and downregulated AQP5 protein in parotid glands of streptozotocin-induced diabetic rats. Biochimica et Biophysica Acta, 1810(5), 543-54, doi: 10.1016/j.bbagen.2011.01.013.

Wang, G-J., Tomasi, D., Backus, W., Wang, R., Teland, F., Geliebter, A., Korner, J., Bauman, A., Fowler, J. S., Thanos, P. K., Volkow, N. D., 2008. Gastric distention activated satiety circuitry in the human brain. Neuroimage, 39(4), 1824-31, doi: 10.1016/j.neuroimage.2007.11.008.

Watson, C. J., Baghdoyan, H. A., \& Lydic, R., 2010. Neuropharmacology of sleep and wakefulness. Sleep Medicine Clinics, 5(4), 513-28, doi: 10.1016/j.jsmc.2010.08.003.

Watts, A. G., 2017. Great expectations: Anticipatory control of magnocellular vasopressin neurons. Neurons, 93, 1-2, doi: 10.1016/j.neuron.2016.12.033.

White, C. P., Hitchcock, C. L., Vigna, Y. M., \& Prior, J. C., 2011. Fluid retention over the menstrual cycle: 1-year data from the prospective ovulation cohort. Obstetrics and Gynecology International, 138451, doi: 10.1155/2011/138451.

Wolf, A. V., 1950. Osmometric analysis of thirst in man and dog. American Journal of Physiology, 161, 75-86, doi: 10.1152/ajplegacy.1950.161.1.75.

Wolff, K., Tsapakis, E. M., Winstock, A. R., Hartley, D., Holt, D., Forsling M. L., \& Aitchison, K.J., 2006. Vasopressin and oxytocin secretion in response to the consumption of ecstasy in a clubbing population. Journal of Psychopharmacology, 20, 400-10, doi: $10.1177 / 0269881106061514$.

Wood, W., \& Rünger, D., 2016. Psychology of habit. Annual Review of Psychology, 61, 289314, doi: 10.1146/annurev-psych-122414-033417. 
Yaxley, S., Rolls, E. T., Sienkiewicz, Z. T., \& Scott, T. R., 1985. Satiety does not affect gustatory activity in the nucleus of the solitary tract of the alert monkey. Brain Research, 11(347), 85-93.

Yeomans, M. R., Blundell, J. E., \& Leshem, M., 2004. Palatability: response to nutritional need or need-free stimulation of appetite? British Journal of Nutrition, 92(Suppl 1), S314.

Yeomans, M. R., Gray, R. W., Mitchell, C. J., \& True, S., 1997. Independent effects of palatability and within-meal pauses on intake and appetite ratings in human volunteers. Appetite, 29, 61-76.

Yu, J. H., Burns, S., \& Schneyer, C. A., 1982. Prostaglandin E1 induced salivary excretion. Experientia, 38(9), 1077-8, doi: 10.1007/bf01955376.

Zabik, J. E., Sprague, J. E., \& Odio, M., 1993. Interactive dopaminergic and noradrenergic systems in the regulation of thirst in the rat. Physiology \& Behavior, 54, 29-33, doi: 10.1016/0031-9384(93)90039-i.

Zanardi, A., Leo, G., Biagini, G., Zoli, M., 2002. Nicotine and neurodegeneration in ageing. Toxicology Letters, 129(1-3), 207-15, doi: 10.1016/S0378-4274(01)00502-1.

Zeisel, S. H., 2011. What choline metabolism can tell us about the underlying mechanisms of fetal alcohol spectrum disorders. Molecular Neurobiology, 44, 185-91.

Zimmerman, C. A., Lin, Y-C., Leib, D. E., Guo, L., Huey, E. L., Daly, G. E., Chen, Y., \& Knight, Z. A., 2016. Thirst neurons anticipate the homeostatic consequences of eating and drinking. Nature, 537(7622), 680-4, doi: 10.1038/nature18950.

Zocchi, D., Wennemuth, G. \& Oka, Y., 2017. The cellular mechanism for water detection in the mammalian taste system. Nature Neuroscience, 20(7), 927-33. 